\title{
Covalent Uranium Carbene Chemistry
}

Matthew Gregson, Ashley J. Wooles, Oliver J. Cooper, and Stephen T. Liddle*

School of Chemistry, University of Nottingham, University Park, Nottingham, NG7 2RD, UK.

*E-mail: stephen.liddle@nottingham.ac.uk

\begin{abstract}
After seminal reports of covalent uranium carbene $U=C$ complexes in the 1980 s by Gilje, the area fell dormant for around thirty years. However, in the past five years there has been a resurgence of interest in the area. Despite recent advances, the classification of these $U=C$ complexes as either methanediides, carbenes or alkylidenes has remained a contentious issue. Herein, we review $U=C$ complexes reported to date, along with reactivity and computational studies, and conclude that although $U=C$ complexes sit mid-way on the continuum between rare earth methanediides and Schrock type alkylidenes they can be justifiably described as carbenes.
\end{abstract}

\section{Introduction}

Carbenes are defined as divalent, 6 electron carbon centres, which can have either a linear or a bent geometry depending on the hybridisation of the orbitals. ${ }^{1}$ A linear geometry implies an $s p$-hybridised carbene centre with two singly occupied non-bonding degenerate orbitals, 
while a bent geometry breaks the degeneracy of these two orbitals, leading to $s p^{2}$ hybridisation of the carbene centre, which can occupy either a singlet or a triplet state. Traditionally transition metal carbene complexes have been classified as either Fischer type or Schrock type carbenes (Figure 1). ${ }^{2,3}$
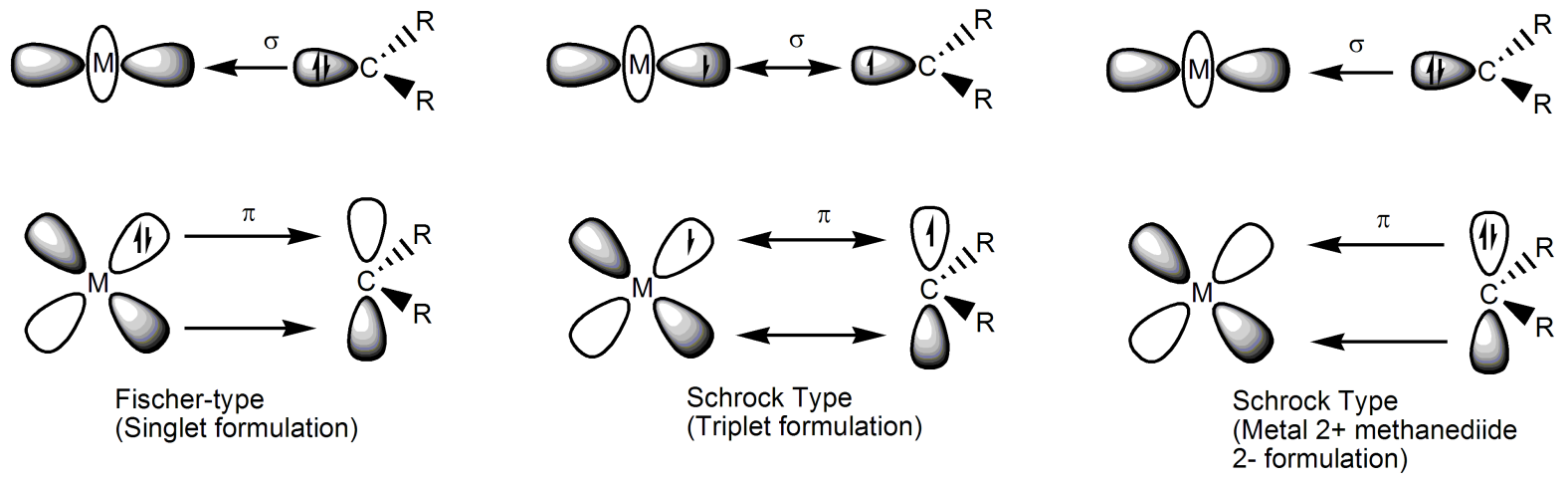

Figure 1. Bonding representations of Fischer and Schrock-type carbenes.

Fischer-type carbenes are prevalent for electron rich metals exhibiting low oxidation states, with the carbene centre typically exhibiting heteroatom stabilisation; they are characterised by $\sigma$-donation of electron density towards a vacant metal $d$-orbital and $\pi$-back donation from a filled metal $d$-orbital into the vacant $p_{\pi}$ orbital at the carbene. This is classified as a donoracceptor interaction. The vacant $p_{z}$ orbital at the carbene centre is higher in energy than the $d_{\pi}$-orbitals, therefore the majority of the $\pi$ electron density remains at the metal centre resulting in an electrophilic carbene centre. Schrock-type carbenes are prevalent for electronpoor metals with high oxidation states, where in most cases the carbene centre is coordinated by alkyl substituents. The bonding in these systems can be considered as a covalent double bond between two triplet centres. The triplet formulation emphasises the covalent combination, much as two triplet methylidene fragments can be combined to give ethylene, but an equally valid arrangement would be to pair a dicationic metal fragment with a dianionic geminal dianion as shown in Figure 1 also (see below). With Schrock carbenes the 
$p_{z}$ orbital of the carbene is lower in energy than the metal $\pi$-orbitals, therefore there is more $\pi$-electron density at the carbene, thus resulting in a nucleophilic carbene centre.

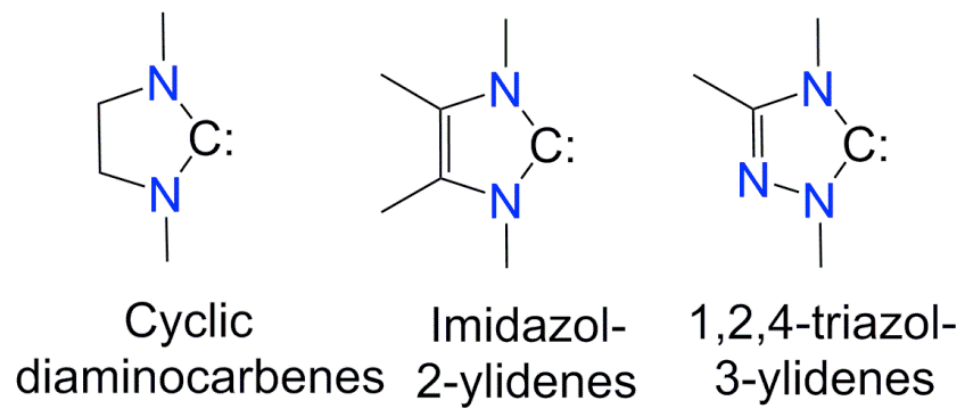

Figure 2. Examples of NHCs.

There is a separate, although well reported class of carbenes, namely $N$-heterocyclic carbenes (NHCs), (Figure 2). ${ }^{1}$ NHCs can be considered to be analogous to Fischer carbenes as the carbene centre is stabilized by the substituents on the carbon. NHCs can stabilize metal centres, with NHC-bound catalysts largely superceding related phosphine-bound catalysts. Whilst there is agreement that NHCs bond to metals through a dative, donor-acceptor interaction, the issue of $\pi$-bonding is contentious. DFT calculations coupled with photoelectron spectroscopy indicate little to no $\mathrm{M} \rightarrow \mathrm{NHC} \pi$-bonding in some group 10 complexes. ${ }^{4,5}$ However, various structural and computational studies on late transition metal NHC complexes ( $\mathrm{Rh}, \mathrm{Ir}, \mathrm{Pt}, \mathrm{Cu}, \mathrm{Ag}$ and $\mathrm{Au}$ ) reveal $\pi$-back bonding character of between 10 $30 \%$ of the total attractive interaction. ${ }^{6-13}$ Reports of uranium NHCs have suggested that there may be some $\mathrm{U} \rightarrow \mathrm{NHC} \quad \pi$-character in $\left[\mathrm{U}\left\{\mathrm{N}\left(\mathrm{SiMe}_{3}\right)_{2}\right\}_{3}\left(\mathrm{Me}_{4} \mathrm{IMC}\right)\right] \quad\left(\mathrm{Me}_{4} \mathrm{IMC}=\right.$ tetramethylimidazol-2-ylidene), ${ }^{14}$ while a report of an isoelectronic and isolobal gallium heterocycle bound to uranium in $\left[\left\{\mathrm{N}\left(\mathrm{CH}_{2} \mathrm{CH}_{2} \mathrm{NSiMe}_{3}\right)_{3}\right\} \mathrm{U}\left\{\mathrm{Ga}(\mathrm{NArCH})_{2}\right\}(\mathrm{THF})\right](\mathrm{Ar}=2,6-$ diisopropylphenyl), ${ }^{15}$ revealed donation of electron density from the gallium centre to uranium in both $\sigma$ and $\pi$ - components of the U-Ga bond. However, as NHCs represent their own class of carbenes, ${ }^{1,16-18}$ and they are overwhelmingly dative donors reviewed 
elsewhere, ${ }^{19}$ they will not be discussed in detail here because the focus of this review is on covalent double bond uranium carbenes.

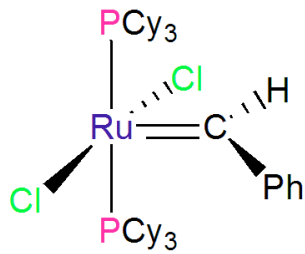

1st Generation Grubbs Catalyst

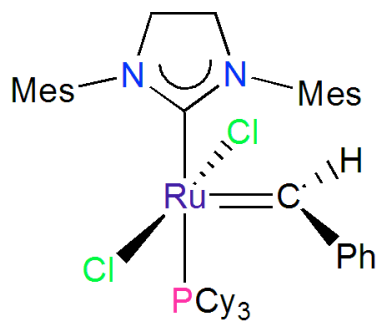

2nd Generation Grubbs Catalyst

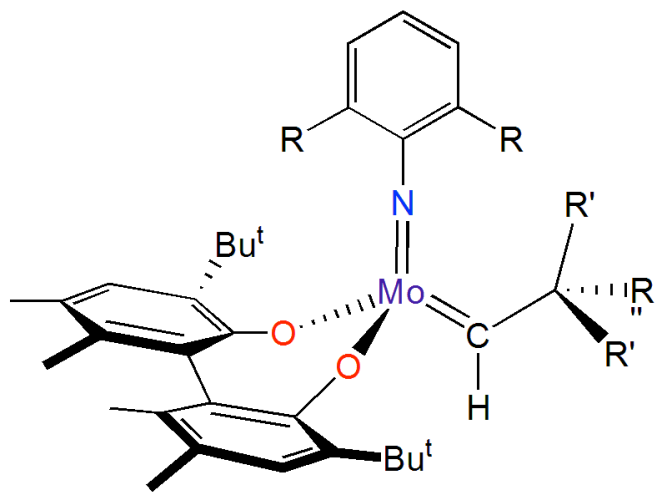

Schrock Catalyst.

Mes $=$ 2,4,6-trimethylphenyl

Figure 3. Examples of TM-carbene catalysts.

The importance of transition metal carbene complexes cannot be understated, as they have found application as intermediate complexes in a range of synthetic reactions. Transition metal alkylidenes have found applications in olefin metathesis, ring closing metathesis, cyclopropanations and Fischer-Tropsch processes, with nucleophilic Schrock-type alkylidenes, such as Tebbe's reagent, being employed in Wittig-type reactions. ${ }^{20-25}$ The importance of metal-carbon multiple bonds has been highlighted by the award of the Nobel Prize in Chemistry in 2005 to Chauvin, Grubbs and Schrock and selected examples are shown in Figure $3 .^{26-28}$ The classification of $f$-block carbenes has proven somewhat controversial in recent years, with Cavell's initial report of $\left[\mathrm{Sm}\left(\mathrm{BIPM}^{\mathrm{TMS}}\right)\left(\mathrm{NCy}_{2}\right)\right]$ $\left(\mathrm{BIPM}^{\mathrm{TMS}}=\left\{\mathrm{C}\left(\mathrm{PPh}_{2} \mathrm{NSiMe}_{3}\right)_{2}\right\}^{2-}\right)$ describing the complex as a methanediide, ${ }^{29}$ while Liddle reported that $\left[\mathrm{Y}\left(\mathrm{BIPM}^{\mathrm{TMS}}\right)\left(\mathrm{CH}_{2} \mathrm{SiMe}_{3}\right)(\mathrm{THF})\right]$ was best described as an alkyl-alkylidene complex, ${ }^{30}$ but in recent years complexes of this type have also been described as nucleophilic carbenes. ${ }^{31,32}$ Due to the core like nature of the $4 f$-orbitals, the capacity for backbonding of electron density from the metal to carbene in lanthanide complexes is minimal (Figure 4), however, the 5 -orbitals on uranium are accessible for bonding and are 
able to exhibit modest covalency when bonding towards carbenes. It should be noted that $6 d$ orbitals are also in principle available to engage in multiple bonds between uranium and carbon and indeed they do contribute to some extent, but calculations suggest that $5 f$-orbital contributions dominate (Table 1). Although the bis-phosphorus stabilised methanediide complexes described herein (vide infra) are in fact 8 electron centres rather than 6 electron centres, as per the textbook definitions of a carbene, the fact that a Schrock alkylidene can be formulated as a $\mathrm{R}_{2} \mathrm{C}^{2-}$ methanediide and a $\mathrm{R}_{3} \mathrm{Ta}^{2+}$ fragment means that the assignment of a carbene is these cases is valid, Figure $1 .^{33,34}$ For the majority of complexes described herein, there is more than one way to represent the electronic structure of the P-substituted carbenes. Many of these forms invoke formal charges, however this can result in cluttered and unclear diagrams. Therefore, structures are drawn with classical double bonds for clarity and to account for all electron pairs, and where the bond is highly polarised we highlight this in the text.

Due to the relatively low level of covalency in $f$-block carbene complexes, stabilising groups $\alpha$ - to the carbene centre have to date been required, particularly phosphorus subsituents. It has been calculated that a $\mathrm{PH}_{2}$ group is able to stabilise a carbanion charge by up to $-89.1 \mathrm{kJmol}^{-}$ ${ }^{135-37}$ and phosphorus(V) substituents would be expected to provide even better stabilisation. However, and like Schrock alkylidenes, in such systems there is a high degree of charge accumulation at the carbene centre and so such species tend to be nucleophilic, which also reflects the relative energies of the uranium and carbene frontier orbitals. 


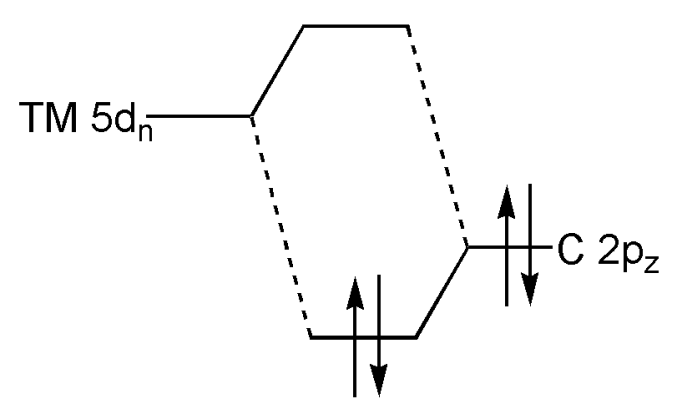

(A)

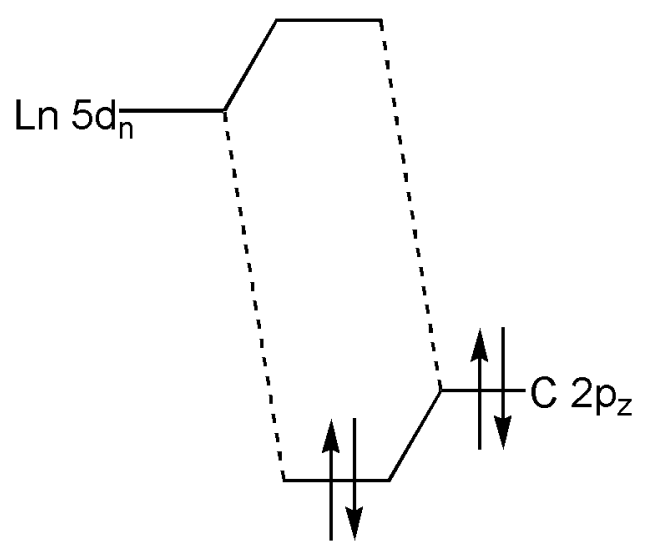

(B)

Figure 4.Qualitative comparison of the relative energies between $T M\left(5 d_{\pi}\right)$ (a) and $\operatorname{Ln}\left(5 d_{\pi}\right)$ (b) with C (2p $p_{z}$ orbitals in Schrock-type carbenes. Adapted from Giesbrecht and Gordon. ${ }^{38}$

\section{Mono-Phosphorus-Stabilised Uranium Carbenes}
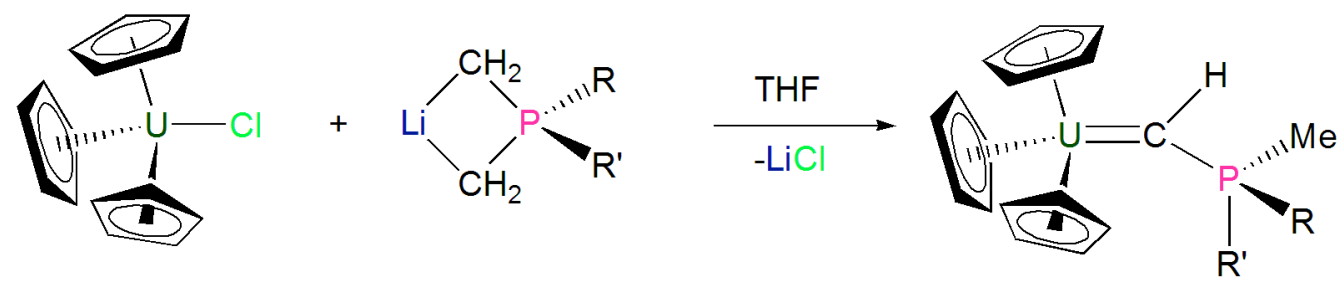

$$
\begin{aligned}
& R=M e, R^{\prime}=P h, 1 \\
& R=R^{\prime}=P h, 2 \\
& R=R^{\prime}=M e, 3
\end{aligned}
$$

Scheme 1. Synthesis of 1-3.

The first uranium carbene complexes were reported by Gilje and Cramer in 1981-82 with the reports of $\left[(\mathrm{Cp})_{3} \mathrm{U}=\mathrm{CHPMe} \mathrm{RPh}\right](\mathrm{R}=\mathrm{Me}, \mathbf{1} ; \mathrm{R}=\mathrm{Ph}, 2)$, which were prepared from the 
reaction of $\left[\mathrm{U}(\mathrm{Cp})_{3} \mathrm{Cl}\right]$ with the lithium salt $\left[\mathrm{Li}\left(\mathrm{CH}_{2}\right)\left(\mathrm{CH}_{2}\right) \mathrm{PRPh}\right]\left(\right.$ Scheme 1) ${ }^{39-41}$ Complex 1 was structurally characterised by X-ray diffraction studies that revealed a uranium-carbon distance of 2.29(3) $\AA$, which, at the time, was the shortest U-C distance known, and this value can be compared to the sum of the covalent bond radii of uranium and carbon of $2.45 \AA$ for a single bond. ${ }^{42}$ In 1988 this series was extended further by Gilje and Schmidbaur, with the reported preparation of $\left[(\mathrm{Cp})_{3} \mathrm{U}=\mathrm{CHPMe}_{3}\right](\mathbf{3}){ }^{43}$ Complex 3 was reported to have a U-C distance of 2.293(2) $\AA$, which is statistically indistinguishable to the U-C distance in $\mathbf{1} .^{39-42}$ The short U-C distances, together with the three-coordinate nature of the carbon centre, allowed multiple bond character to be ascribed to the $\mathrm{U}=\mathrm{C}$ bond, and in the years that followed the preparation of $\mathbf{1}$ and $\mathbf{2}$ a raft of reactivity studies were performed in order to assess the nature of the formal $\mathrm{U}=\mathrm{C}$ double bond.

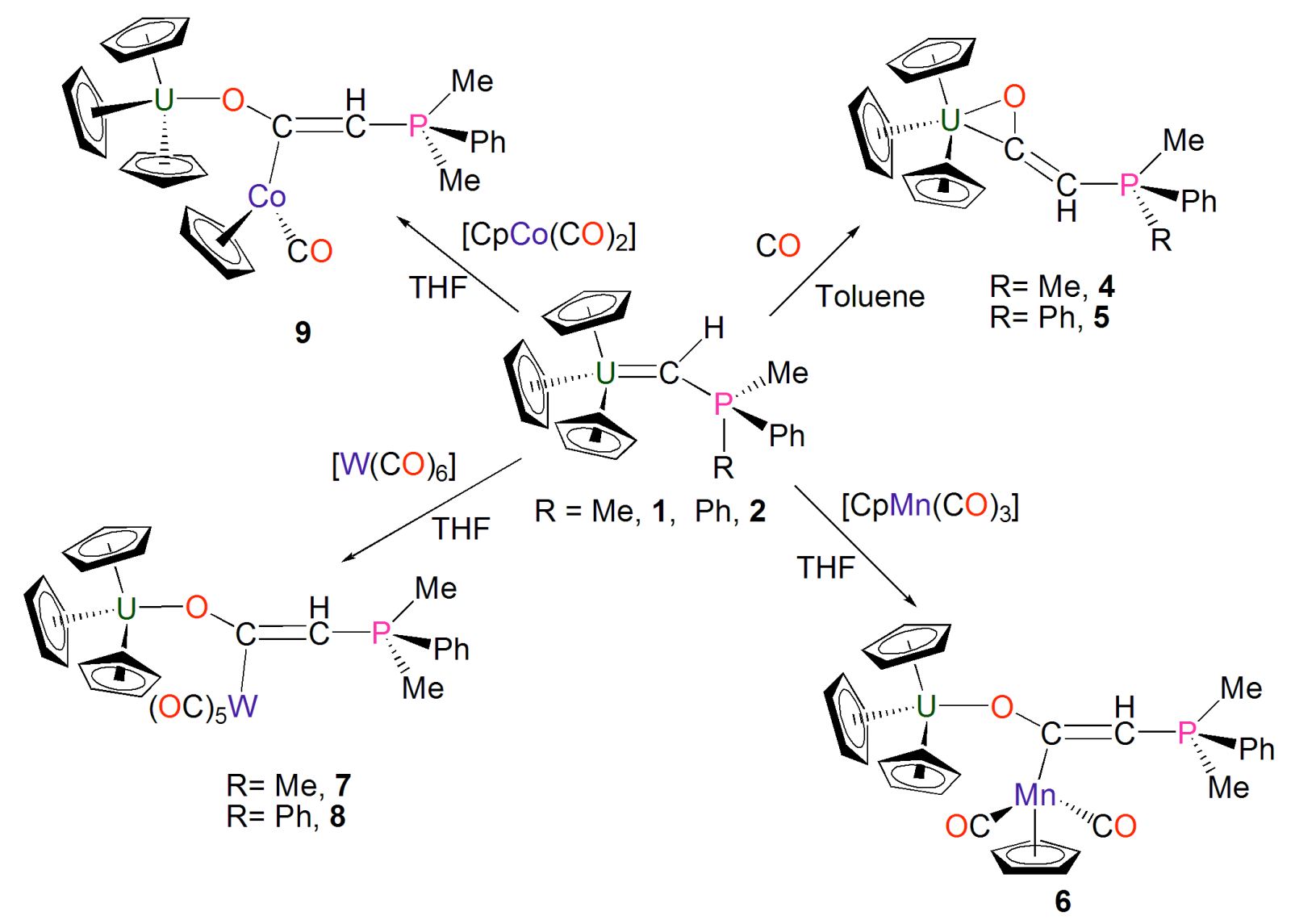

Scheme 2. Reactivity of 1-2 towards metal carbonyls. 
The reactions of $\mathbf{1}$ and $\mathbf{2}$ towards carbon monoxide were investigated, and each were shown to react with $\mathrm{CO}$ via an insertion into the $\mathrm{U}=\mathrm{C}$ bond to afford the $\beta$-ketoylide derivatives $\left[(\mathrm{Cp})_{3} \mathrm{U}(\mathrm{OC}=\mathrm{CHMePhR}](\mathrm{R}=\mathrm{Me}, \mathbf{4} ; \mathrm{R}=\mathrm{Ph}, \mathbf{5})(\right.$ Scheme 2$) .{ }^{40}$ Structural characterisation of 4 revealed the $\mathrm{CO}$ fragment to be bound to uranium in an $\eta^{2}$-manner. Further reactivity of 1 and $\mathbf{2}$ towards coordinated carbonyls was reported, with the reactions of $\mathbf{1}$ or $\mathbf{2}$ with a range of transition metal carbonyls $\left[\mathrm{M}(\mathrm{CO})_{\mathrm{n}} \mathrm{Cp}_{\mathrm{x}}\right](\mathrm{M}=\mathrm{Mn}, \mathrm{n}=3, \mathrm{x}=1 ; \mathrm{M}=\mathrm{W}, \mathrm{n}=6, \mathrm{x}=0 ; \mathrm{M}=\mathrm{Co}$, $\mathrm{n}=2, \mathrm{x}=1)$ affording the insertion products $\left[(\mathrm{Cp})_{3} \mathrm{U}\left\{\mathrm{OC}(\mathrm{R}) \mathrm{C}(\mathrm{H}) \mathrm{PMe}_{2} \mathrm{Ph}\right]\left(\mathrm{R}=\mathrm{CpMn}(\mathrm{CO})_{2}\right.\right.$, 6) $\left[(\mathrm{Cp})_{3} \mathrm{U}\left\{\mathrm{OC}(\mathrm{R}) \mathrm{C}(\mathrm{H}) \mathrm{PMePhR}^{\prime}\right] \quad\left(\mathrm{R}=\mathrm{W}(\mathrm{CO})_{5}: \mathrm{R}^{\prime}=\mathrm{Me}, \quad 7 ; \quad \mathrm{R}^{\prime}=\mathrm{Ph}, \quad 8\right)\right.$ and $\left[(\mathrm{Cp})_{3} \mathrm{U}\left\{\mathrm{OC}(\mathrm{R}) \mathrm{C}(\mathrm{H}) \mathrm{PMe}_{2} \mathrm{Ph}\right](\mathrm{R}=\mathrm{CpCo}(\mathrm{CO}), 9)(\right.$ Scheme 2$) .{ }^{44-46}$ In contrast to 4 the structural characterisation of $\mathbf{6 , 8}$ and 9 revealed the inserted carbonyl to be bound to uranium in an $\eta^{1}$ - rather than an $\eta^{2}$ - fashion. ${ }^{44-46}$ Concurrent to the reactivity studies of $\mathbf{1}$ and $\mathbf{2}$ towards carbonyls, Gilje and co-workers reported reactivity towards other organic substrates (Scheme 3).

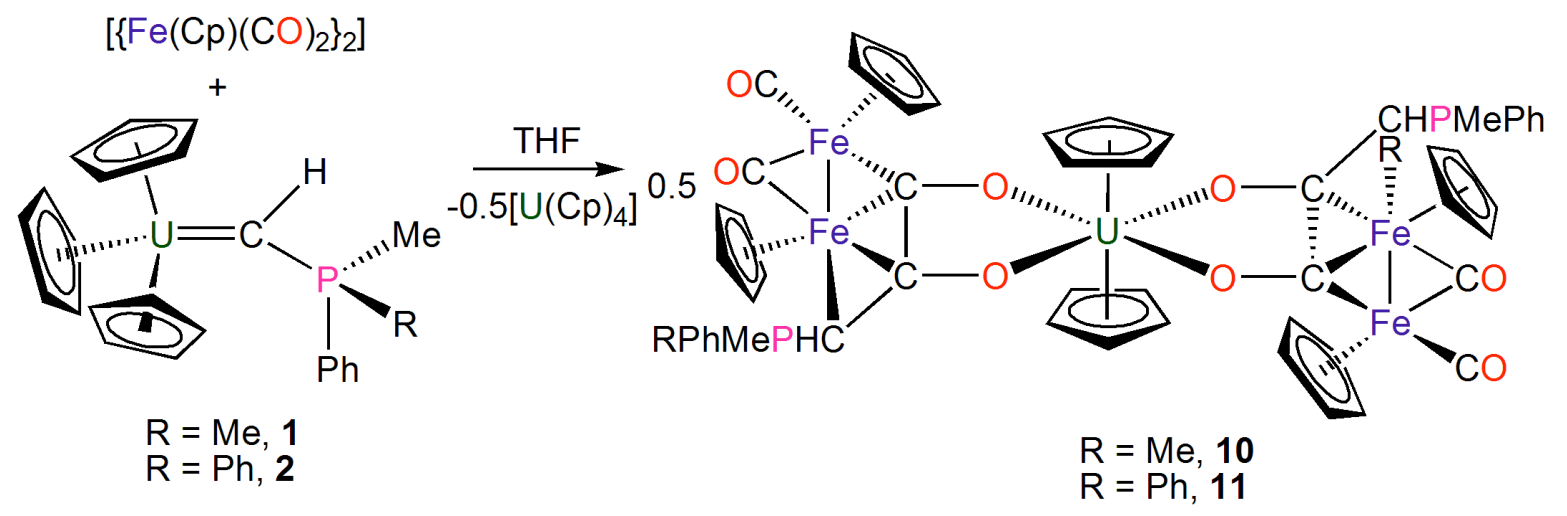

Scheme 3. Further reactivity of 1-2 towards metal carbonyls.

In contrast to the reactivity of $\mathbf{1}$ and $\mathbf{2}$ towards metal carbonyls to afford 6-9 via insertion reactions, the reaction of $\mathbf{1}$ or $\mathbf{2}$ with bimetallic $\left[\mathrm{Fe}(\mathrm{Cp})(\mathrm{CO})_{2}\right]_{2}$ afforded $\left[\mathrm{U}(\mathrm{Cp})_{2}\left\{\mathrm{Fe}_{2}(\mathrm{Cp})_{2}(\mathrm{CO})(\mu-\mathrm{CO})\left[\mu-\mathrm{C}(\mathrm{H})(\mathrm{PMePhR})\left(\mathrm{C}_{2} \mathrm{O}_{2}\right)-\kappa^{2} \mathrm{O}, \mathrm{O}^{\prime}\right]\right\}\right](\mathrm{R}=\mathrm{Me}, \mathbf{1 0} ; \mathrm{R}=\mathrm{Ph}, \mathbf{1 1})$ and $\left[\mathrm{U}(\mathrm{Cp})_{4}\right]$, (Scheme 3). ${ }^{47}$ The reaction was monitored by NMR spectroscopy, which 
indicated the formation of an intermediate analogous to 6-9 before conversion to $\mathbf{1 0}$ and $\mathbf{1 1}$. The formation of $\mathbf{1 0}$ and $\mathbf{1 1}$ proceeded via the coupling of a bridging and terminal carbonyl, with the former terminal carbonyl coupling to the ylide fragment.

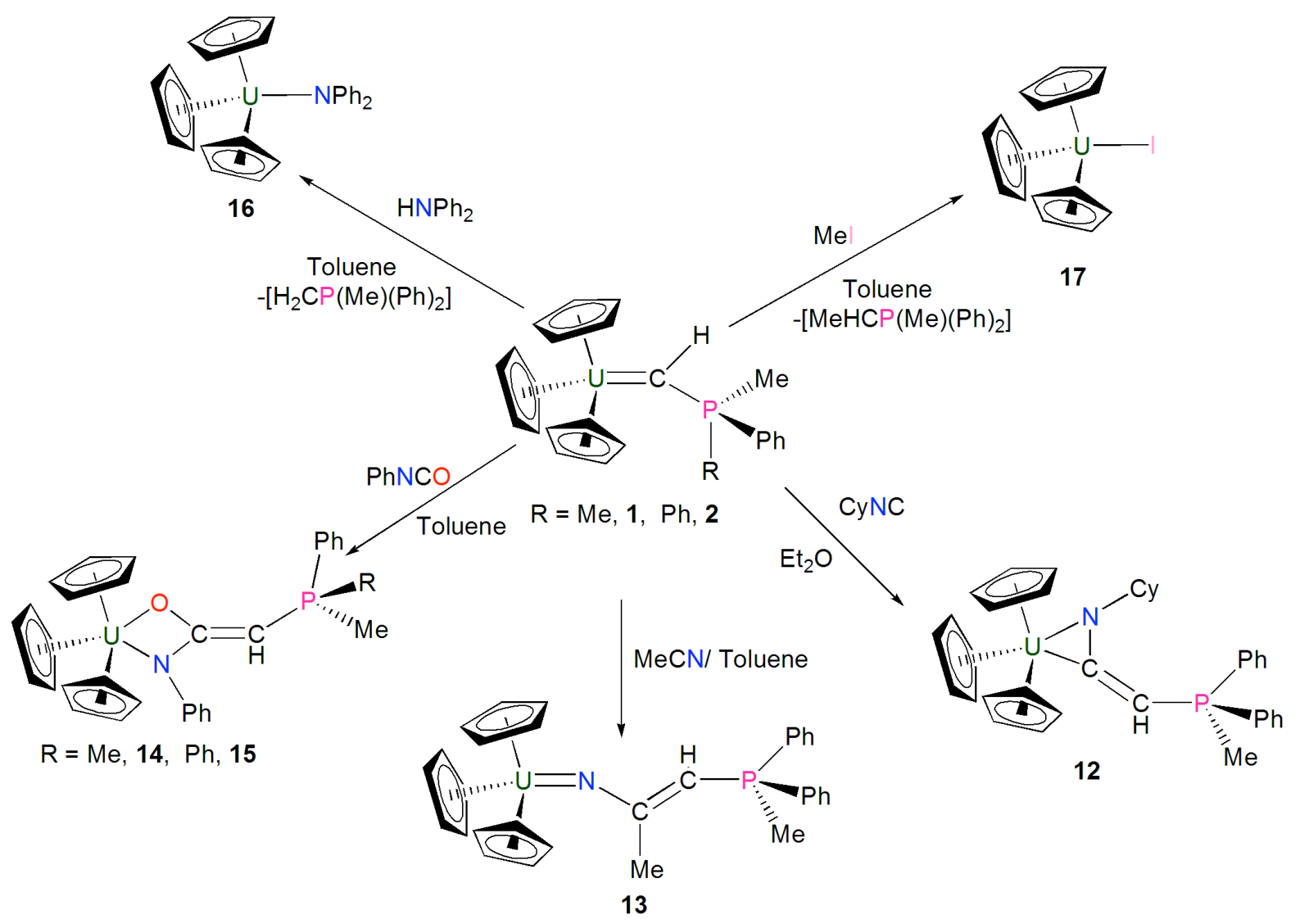

Scheme 4. Reactivity of 1-2 towards nitriles and cyanates.

The reaction of $\mathbf{1}$ or $\mathbf{2}$ towards a range of nitriles and isocyanates afforded insertion products in each case, with the reaction of 2 with cyclohexyl-isocyanide affording $\left[(\mathrm{Cp})_{3} \mathrm{U}\left\{\eta^{2}-\right.\right.$ $\left.\left.\mathrm{N}(\mathrm{Cy}) \mathrm{C}=\mathrm{CHP}(\mathrm{Me})(\mathrm{Ph})_{2}\right\}\right] \quad(\mathbf{1 2})^{48}$ and the reaction of $\mathbf{2}$ with acetonitrile affording $\left[(\mathrm{Cp})_{3} \mathrm{U}\left\{\mathrm{NC}(\mathrm{Me})=\mathrm{CHPMePh}_{2}\right] \quad(\mathbf{1 3}) \quad(\right.$ Scheme 4$) .{ }^{49}$ Both 12 and $\mathbf{1 3}$ were structurally characterised, and different bonding motifs were observed in each case. In $\mathbf{1 3}$ the first example of a uranium imido interaction is observed, which exhibits a very short $U=N$ distance of 2.06(1) $\AA$; this was the shortest $\mathrm{U}=\mathrm{N}$ distance known at the time of publication, whereas in the case of $\mathbf{1 2}$ a uranaazacyclo-propene motif was observed, with the uranium 
bound to both the nitrogen and carbon centres. Similarly, the reaction of either $\mathbf{1}$ or $\mathbf{2}$ with phenyl isocyanate afforded $\left[(\mathrm{Cp})_{3} \mathrm{U}\left\{\kappa^{2}-\mathrm{N}, \mathrm{O}-\mathrm{NPh}(\mathrm{O}) \mathrm{C}=\mathrm{CHPMePhR}\right\}\right],(\mathrm{R}=\mathrm{Me}, \mathbf{1 4} ; \mathrm{R}=\mathrm{Ph}$, 15), and structural characterisation of $\mathbf{1 4}$ revealed delocalisation of charge about the NCO linkage leading to a four membered metallocyclic ring. The basicity of the $\alpha$-carbon in $\mathbf{2}$ was shown in the reaction of $\mathbf{2}$ with diphenylamine, which afforded the uranium amide $\left[(\mathrm{Cp})_{3} \mathrm{U}\left(\mathrm{NPh}_{2}\right)\right](\mathbf{1 6})^{50}$ with concomitant elimination of the ylide $\left[\mathrm{H}_{2} \mathrm{CP}(\mathrm{Me})(\mathrm{Ph})_{2}\right]$. A similar ylide elimination was reported in the reaction of $\mathbf{1}$ or $\mathbf{2}$ with methyliodide which afforded $\left[(\mathrm{Cp})_{3} \mathrm{UI}\right](\mathbf{1 7})^{51}$ with elimination of $\left[\mathrm{MeHCP}(\mathrm{Me})(\mathrm{Ph})_{2}\right]$.

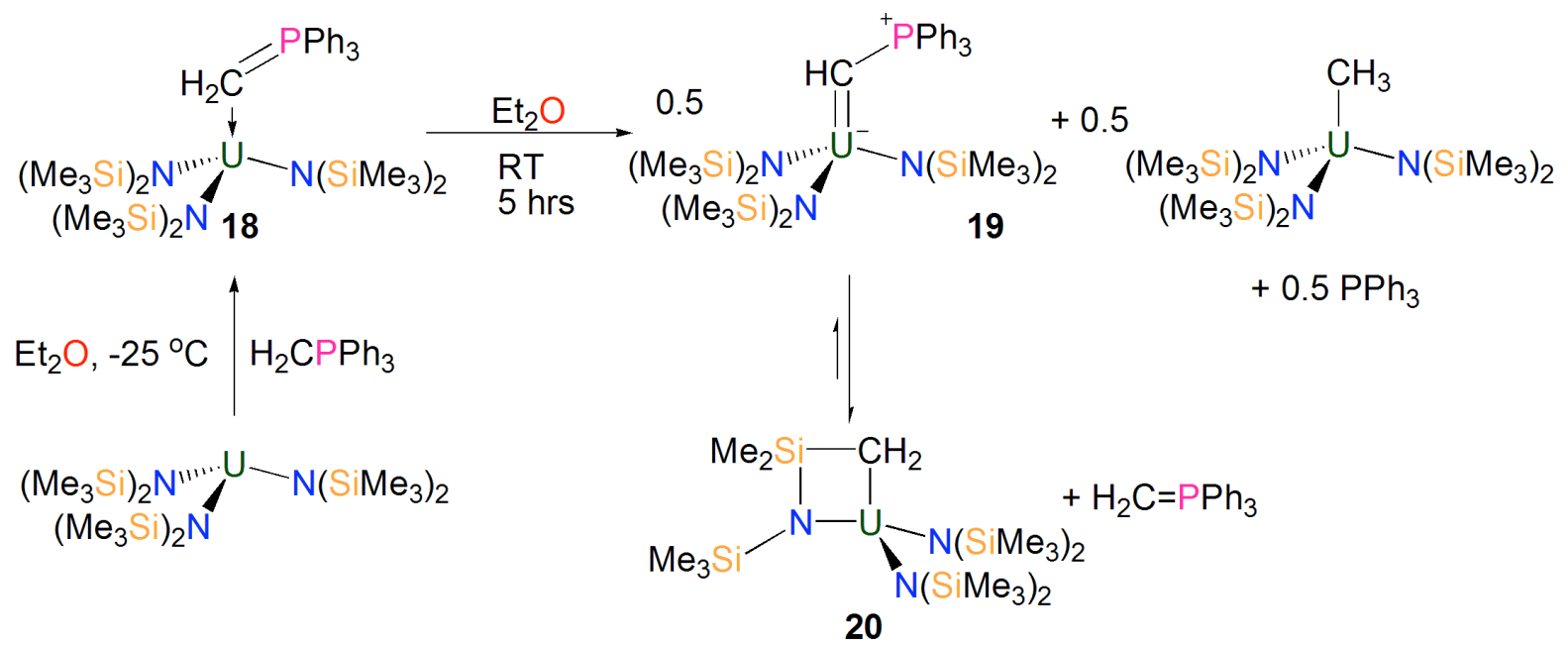

Scheme 5. Synthesis of 18-20.

Following Gilje's last reports utilising the $\left\{\mathrm{HCPR}_{3}\right\}$ ligand system in $1990,{ }^{44,52}$ Hayton reported an alternative preparative route to $\left\{\mathrm{HCPR}_{3}\right\}$-derived uranium carbenes, via the one electron oxidation of the trivalent ylide adduct precursor $\left[\mathrm{U}\left(\mathrm{CH}_{2} \mathrm{PPh}_{3}\right)\left\{\mathrm{N}\left(\mathrm{SiMe}_{3}\right)_{2}\right\}_{3}\right]$ (18) which afforded $\left[\mathrm{U}=\mathrm{CHPPh}_{3}\left\{\mathrm{~N}\left(\mathrm{SiMe}_{3}\right)_{2}\right\}_{3}\right]$ (19) (Scheme 5). ${ }^{53}$ The reaction proceeds via an intramolecular $\mathrm{H}^{\cdot}$ atom transfer to afford 19 along with the by-products $\left[\mathrm{U}\left(\mathrm{CH}_{3}\right)\left\{\mathrm{N}\left(\mathrm{SiMe}_{3}\right)_{2}\right\}_{3}\right]$ and triphenylphosphine. Complex 19 exists in equilibrium with the metallocycle $\left[\mathrm{U}\left(\mathrm{CH}_{2} \mathrm{SiMe}_{2} \mathrm{NSiMe}_{3}\right)\left\{\mathrm{N}\left(\mathrm{SiMe}_{3}\right)_{2}\right\}_{2}\right]$ (20) and the ylide $\mathrm{CH}_{2}=\mathrm{PPh}_{3}$ (Scheme 5). The equilibria is dependent on both solvent and temperature, with polar solvents favouring 
the formation of the metallocycle, whereas storage at low temperatures helps maintain the carbene complex and prevent the formation of the metallocycle. Structural investigations of 19 reveal a $\mathrm{U}=\mathrm{C}$ bond distance of $2.278(8) \AA$ which is statistically equivalent to the distances observed in $\mathbf{1}$ and $\mathbf{3}$.

\section{Bis-Phosphorus-Stabilised Uranium Carbenes}

The carbene complexes 1-3 and 19 uniformally exhibit a single $\alpha$-phosphorus substituent, which is able to stabilise the negative charge on the carbon centre, and to increase this stabilisation two $\alpha$-phosphorus substituents have been developed in recent years. Ligands of this type have been utilised in the preparation of transition metal and lanthanide carbenes, ${ }^{31}$ and in recent years they have found extensive utility in uranium carbene chemistry. The two ubiquituous ligands of this are type are bis-iminophosphoranomethanediide $\left\{\mathrm{C}\left(\mathrm{PPh}_{2} \mathrm{NR}\right)_{2}\right\}^{2-}$ $\left(\mathrm{BIPM}^{\mathrm{R}}\right)$, and bis-thiophosphoranomethanediide $\left\{\mathrm{C}\left(\mathrm{PPh}_{2} \mathrm{~S}\right)_{2}\right\}^{2-}$ (SCS). There are several resonance forms possible for these species, however the dipolar resonance form $\mathrm{R}^{-} \mathrm{P}^{+} \mathrm{C}^{2-} \mathrm{P}^{+} \mathrm{R}^{-}$ (I) has recently been found to be the most accurate description for these ligands, ${ }^{54}$ although resonance form (II) remains a possibility. ${ }^{55}$ Although reports of the use of SCS and BIPM ${ }^{\mathrm{R}}$ uranium carbenes have been published concurrently in recent years, they will be discussed separately for clarity. 


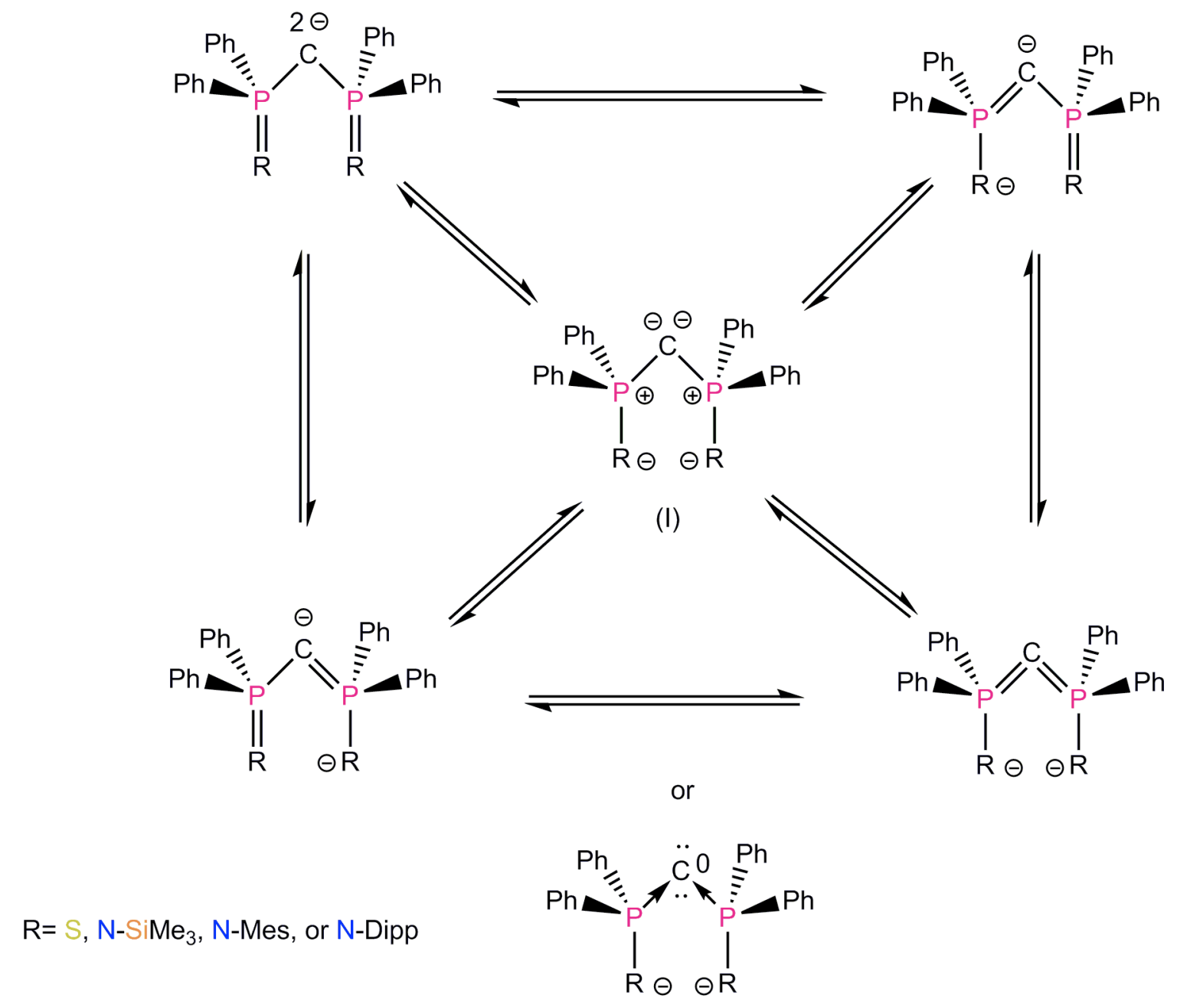

(II)

Figure 5.Resonance Forms of $\left\{B I P M^{R}\right\}^{2-}$ and $\{S C S\}^{2-}$. 


\section{Bis-Thiophosphorano-Stabilised Uranium Carbenes}

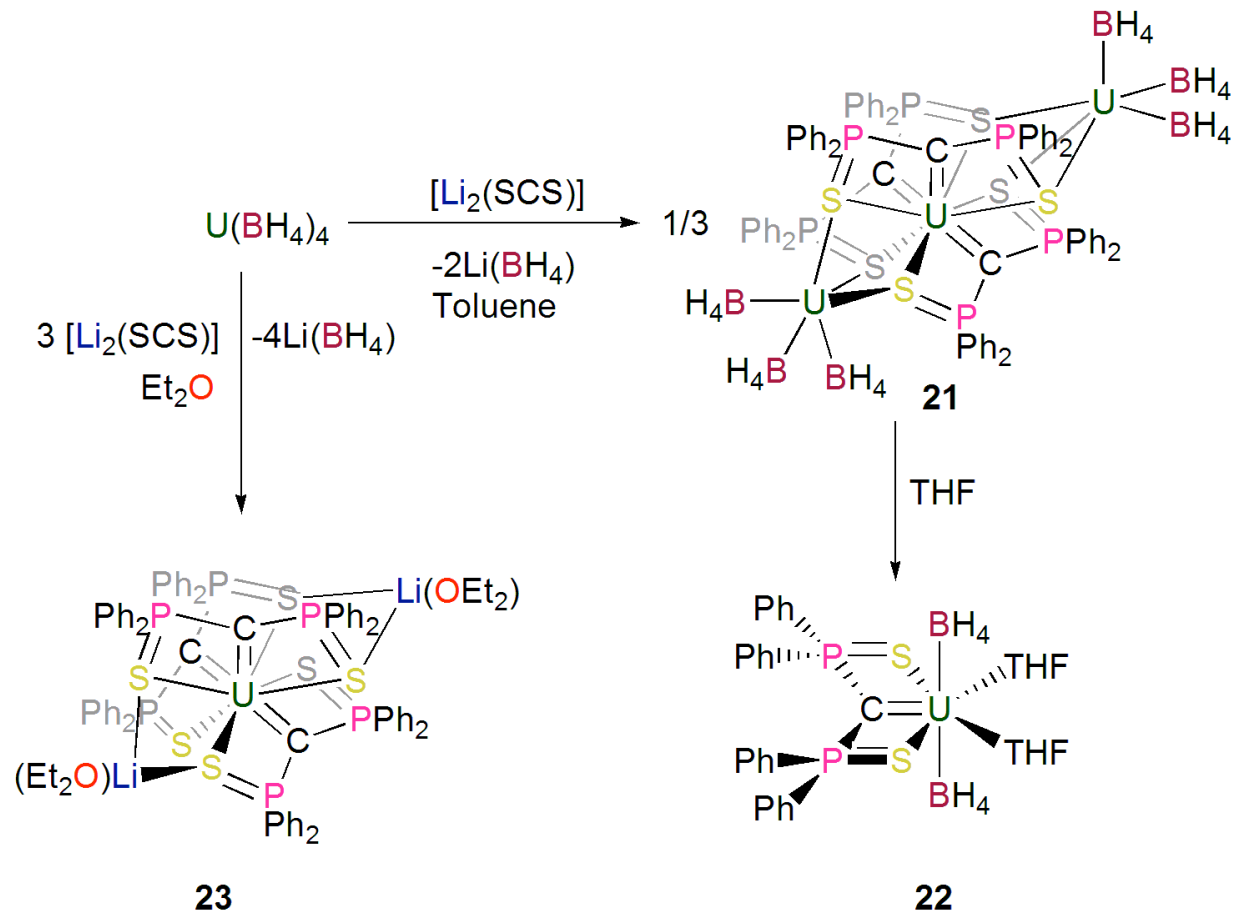

Scheme 6. Synthesis of 21-23.

In 2009, Arligue, Ephritikhine, Le Floch and Mézailles reported that the reaction of $\left[\mathrm{U}\left(\mathrm{BH}_{4}\right)_{4}\right]$ with $\left[\mathrm{Li}_{2}(\mathrm{SCS})\right]$ afforded the tris-carbene complex $\left[\left\{\mathrm{U}\left(\mathrm{BH}_{4}\right)\right\}_{2} \mathrm{U}(\mathrm{SCS})_{3}\right](\mathbf{2 1}),{ }^{56}$ which exhibits three SCS ligands coordinated to one central uranium centre with two additional $\left\{\mathrm{U}\left(\mathrm{BH}_{4}\right)_{3}\right\}^{+}$fragments bound to the sulphur atoms (Scheme 6). The authors showed that 21 could be converted to the mono-carbene species $\left[\mathrm{U}(\mathrm{SCS})\left(\mathrm{BH}_{4}\right)_{2}(\mathrm{THF})_{2}\right](\mathbf{2 2})$ by refluxing in THF for 30 minutes, with coordination of THF facilitating ligand redistribution to give a mononuclear species. The $\mathrm{U}=\mathrm{C}$ bond distance in $\mathbf{2 2}$ was reported to be 2.327(3) $\AA$, which is statistically invariant to the $\mathrm{U}=\mathrm{C}$ distance reported for $\mathbf{1}$ (because of the large standard uncertainty of the latter), but longer than the $\mathrm{U}=\mathrm{C}$ distances reported for 3 and 19, which is likely a result of the increased steric demands of $\{\mathrm{SCS}\}^{2-} v s\left\{\mathrm{HCPR}_{3}\right\}^{2-}$. A DFT and NBO study concluded that a polarised $\mathrm{U}=\mathrm{C}$ double bond is present in $\mathbf{2 2}$. The 
authors also reported the synthesis of $\left[\mathrm{U}(\mathrm{SCS})_{3}\left\{\mathrm{Li}\left(\mathrm{OEt}_{2}\right)\right\}_{2}\right]$ (23) by the reaction of $\left[\mathrm{U}\left(\mathrm{BH}_{4}\right)_{4}\right]$ with three equivalents of $\left[\mathrm{Li}_{2}(\mathrm{SCS})\right]$ in diethylether.

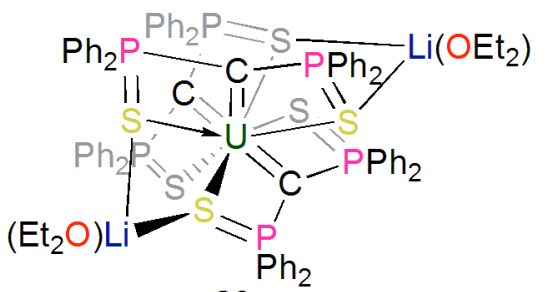

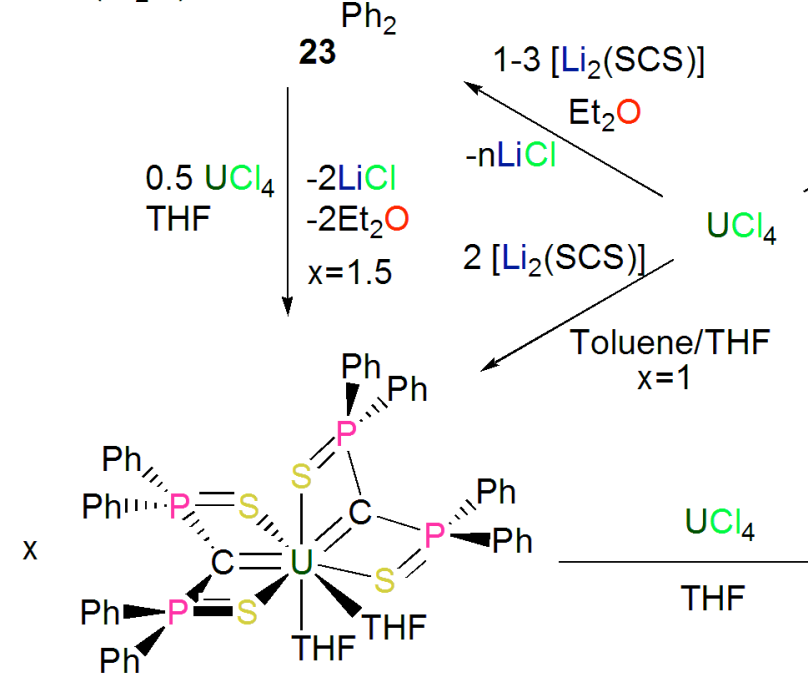

25

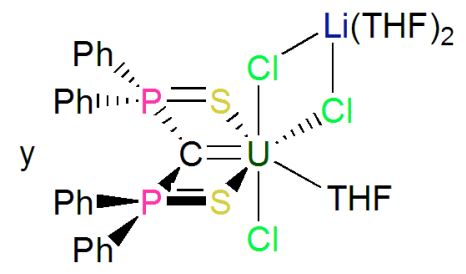

24
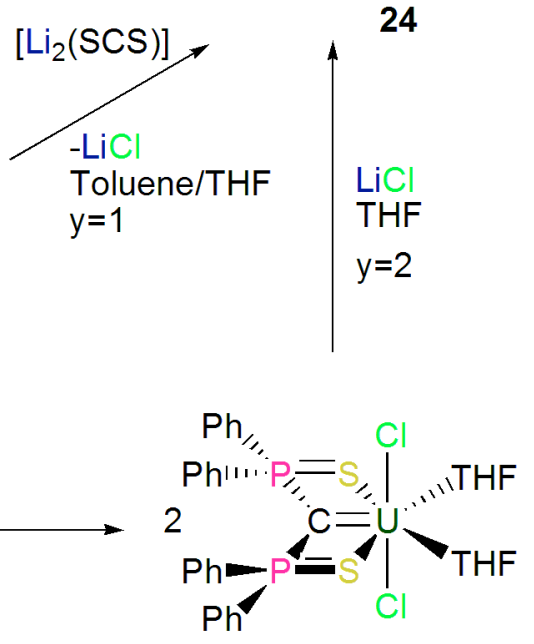

26

Scheme 7. Synthesis of 24-26.

Following the preparation of 21-23, Berthet, Mézailles and Ephritikhine reported the synthesis of a range of $\{\mathrm{SCS}\}^{2-}$ derived uranium carbenes from $\mathrm{UCl}_{4}$, which was a preferred starting material due to the tedious preparation required for $\left[\mathrm{U}\left(\mathrm{BH}_{4}\right)_{4}\right] .{ }^{57,58}$ It was found that in diethylether solutions, the reaction of $\mathrm{UCl}_{4}$ with one, two, or three equivalents of [Li 2 (SCS)] led to the isolation of $\mathbf{2 3}$ (Scheme 7). However, the authors noted that performing the reaction in a THF/toluene mix, allowed $\left[\mathrm{U}(\mathrm{SCS})(\mathrm{Cl})_{3}(\mathrm{THF})\left\{\mathrm{Li}(\mathrm{THF})_{2}\right\}\right]$ (24) and $\left[\mathrm{U}(\mathrm{SCS})_{2}(\mathrm{THF})_{2}\right](\mathbf{2 5})$ to be isolated when utilising the appropriate stoichiometric amount of [Li $\left.\mathrm{L}_{2}(\mathrm{SCS})\right]$ (Scheme 7). It was also reported that the tris-carbene $\mathbf{2 3}$ could be converted to the bis-carbene 25 by reaction with half an equivalent of $\mathrm{UCl}_{4}$, and reaction of 25 with a further equivalent of $\mathrm{UCl}_{4}$ allowed the isolation of the salt free mono-carbene $\left[\mathrm{U}(\mathrm{SCS})(\mathrm{Cl})_{2}(\mathrm{THF})_{2}\right]$ 
(26). ${ }^{58}$ Structural investigations revealed a $\mathrm{U}=\mathrm{C}$ bond distance in $\mathbf{2 4}$ of 2.344(13) $\AA$, which is shorter than the tris- and bis-substituted carbenes $\mathbf{2 3}$ and $\mathbf{2 5}$ which exhibit average $\mathrm{U}=\mathrm{C}$ bond distances of 2.484(3) $\AA$ and 2.395(8) $\AA$, respectively, ${ }^{58}$ due to increased coordination number and steric crowding around the uranium centres.

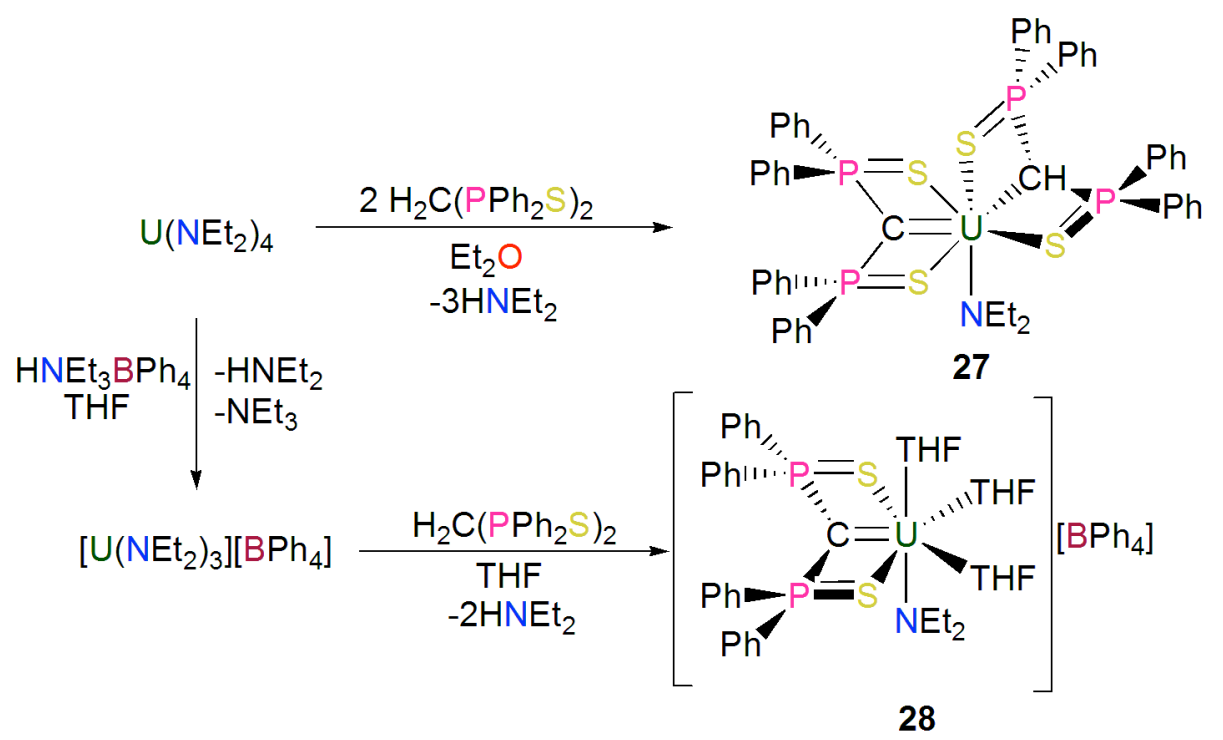

Scheme 8. Synthesis of 27-28.

Following the salt elimination strategies utilised in the preparation of 22-24, an alternative amine elimination procedure was reported $(\mathrm{Scheme} 8) .{ }^{57}$ The reaction of $\left[\mathrm{U}\left(\mathrm{NEt}_{2}\right)_{4}\right]$ with two equivalents of $\mathrm{H}_{2} \mathrm{C}\left(\mathrm{PPh}_{2} \mathrm{~S}\right)_{2}$ was anticipated to afford 25 via the elimination of four equivalents of $\mathrm{HNEt}_{2}$, however this preparation was not straightforward. It was reported that utilising THF as the reaction solvent afforded a mixture of $\mathbf{2 5}$ and [U(SCS)( $\left.\mathrm{NEt}_{2}\right)$ ] in a relative ratio of 73:27, whilst in diethylether the mixed methanide-carbene complex [U(SCS)(SCHS)(NEt 2$)](27)$ was obtained. Fortunately, however, after isolation 27 could be converted to 25 by dissolution in THF and elimination of $\mathrm{HNEt}_{2}{ }^{57}$ Following these difficulties the authors investigated an alternate amide precursor, and the reaction of the cationic uranium complex $\left[\mathrm{U}\left(\mathrm{NEt}_{2}\right)_{3}\right]\left[\mathrm{BPh}_{4}\right]$ with $\mathrm{H}_{2} \mathrm{C}\left(\mathrm{PPh}_{2} \mathrm{~S}\right)_{2}$ was found to cleanly produce the mono-carbene species $\left[\mathrm{U}(\mathrm{SCS})\left(\mathrm{NEt}_{2}\right)(\mathrm{THF})_{3}\right]\left[\mathrm{BPh}_{4}\right](\mathbf{2 8}) .^{57}$ 


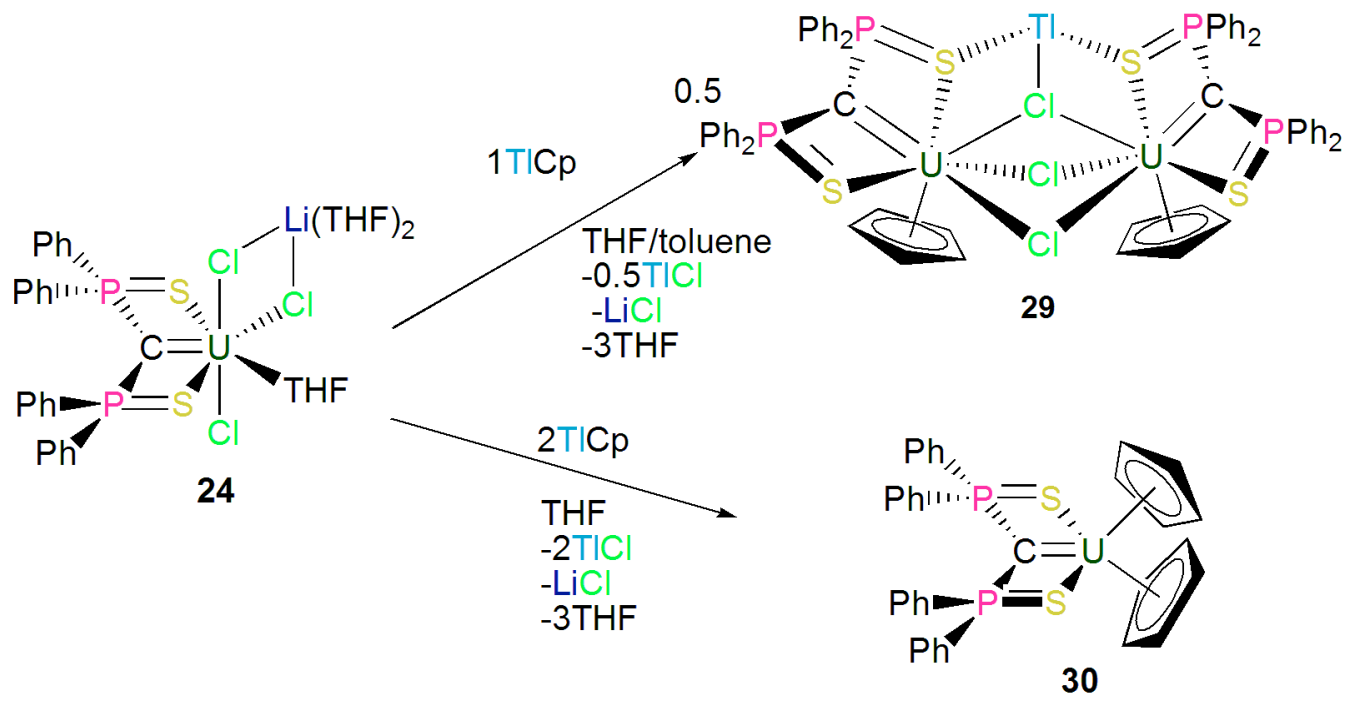

Scheme 9. Synthesis of 29-30.

Following the preparation of 24-28, Berthet, Mézailles and Ephritikhine prepared complexes containing $\pi$-ligands (Scheme 9 ) ${ }^{57}$ The reaction of $\mathbf{2 4}$ with one equivalent of TlCp afforded $\left[\{\mathrm{U}(\mathrm{SCS})(\mathrm{Cp})\}_{2}\left\{(\mu-\mathrm{Cl})_{2}(\mu-\mathrm{TlCl})\right\}\right](\mathbf{2 9})$, while the reaction of $\mathbf{2 4}$ with two equivalents of TlCp afforded the uranium carbene bis-cyclopentadienyl complex $\left[\mathrm{U}(\mathrm{SCS})(\mathrm{Cp})_{2}\right](\mathbf{3 0}) .{ }^{57} \mathrm{The}$ $\mathrm{U}=\mathrm{C}$ bond distance in $\mathbf{3 0}$ of 2.336(4) $\AA$ is statistically indistinguishable from the distance reported for 22, despite the variation in ancillary ligand.
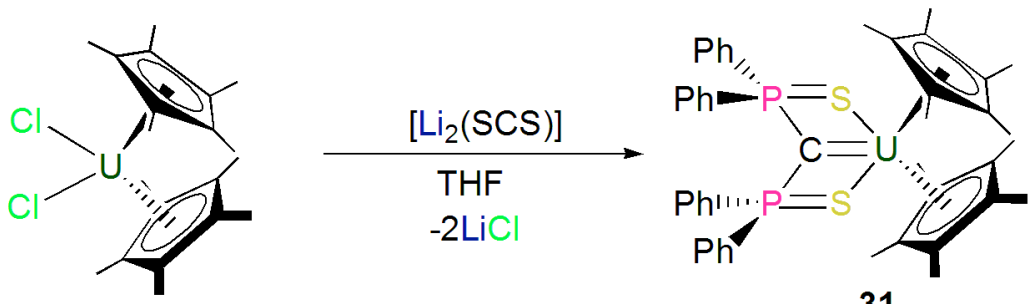

31

Scheme 10. Synthesis of 31.

Attempts to prepare the $\mathrm{Cp}^{*}\left(\mathrm{C}_{5} \mathrm{Me}_{5}\right)$ analogue of $\mathbf{3 0}$ by the reaction of $\mathbf{2 4}$ with two equivalents of $\mathrm{KCp}^{*}$ or $\mathrm{Mg}\left(\mathrm{Cp}^{*}\right) \mathrm{Cl}$ were unsuccessful. However, by employing $\left[\mathrm{U}\left(\mathrm{Cp}^{*}\right)_{2}(\mathrm{Cl})_{2}\right]$ as the starting material and reacting it with one equivalent of $\left[\mathrm{Li}_{2}(\mathrm{SCS})\right]$ the carbene complex $\left[\mathrm{U}(\mathrm{SCS})\left(\mathrm{Cp}^{*}\right)_{2}\right]$ (31) could be readily prepared (Scheme 10$){ }^{57}$ 


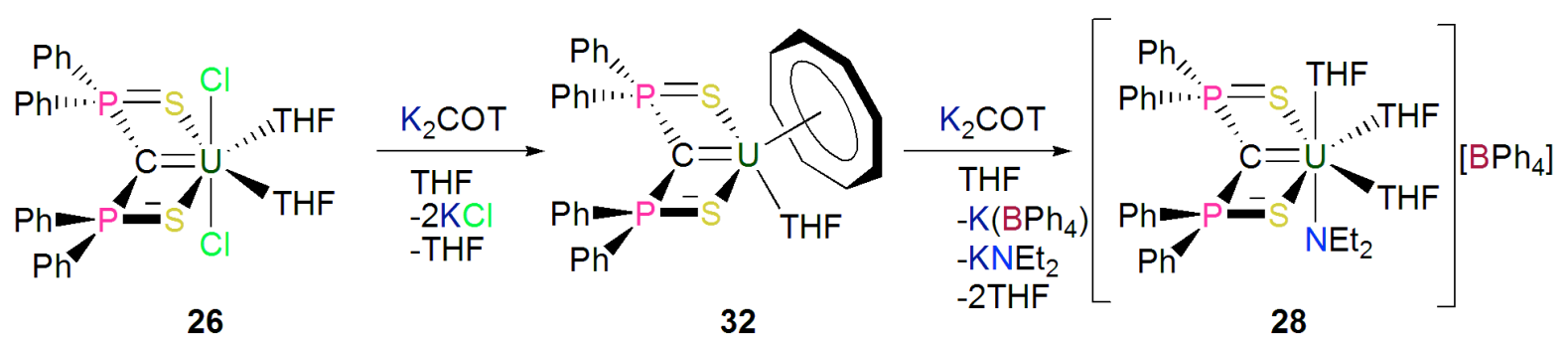

Scheme 11. Synthesis of 32.

The cyclooctatetraenyl (COT) substituted carbene [U(SCS)(COT)(THF)] (32) can be prepared by the reaction of $\left[\mathrm{K}_{2}(\mathrm{COT})\right]$ with either $\mathbf{2 6}$ or 28 (Scheme 11). The $\mathrm{U}=\mathrm{C}$ bond distance in 31 [2.396(4) $\AA$ ] is longer than the corresponding distance in $\mathbf{3 0}$ due to the increased steric demands of $\mathrm{Cp}^{*}$ vs $\mathrm{Cp}$, while the $\mathrm{U}=\mathrm{C}$ distance in 32 [2.351(8) $\left.\AA\right]$ remains similar to the distances reported for $\mathbf{2 4}$ and $\mathbf{3 0 .}$

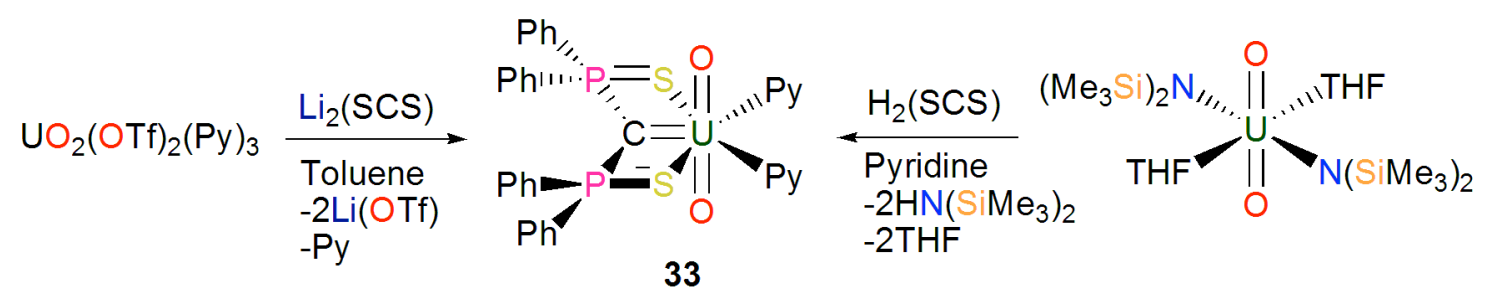

Scheme 12. Synthesis of 33.

The $\{\mathrm{SCS}\}^{2-}$ ligand has also been utilised in uranyl chemistry, and was reported to afford the first example of a covalent uranyl carbene $\left[\mathrm{U}(\mathrm{O})_{2}(\mathrm{SCS})(\mathrm{Py})_{2}\right](33)$, from the reaction of $\mathrm{H}_{2}(\mathrm{SCS})$ or $\left[\mathrm{Li}_{2}(\mathrm{SCS})\right]$ with $\left[\mathrm{U}(\mathrm{O})_{2}\left\{\mathrm{~N}\left(\mathrm{SiMe}_{3}\right)_{2}\right\}_{2}(\mathrm{THF})_{2}\right]$ or $\left[\mathrm{U}(\mathrm{O})_{2}(\mathrm{OTf})_{2}(\mathrm{Py})_{3}\right]$, respectively (Scheme 12). ${ }^{59}$ A structural investigation of 33 revealed a $U=C$ bond distance of $2.430(6) \AA$, which is $\sim 0.1 \AA$ longer than the mononuclear uranium carbenes 22, 24 and 28 despite the $\mathrm{UO}_{2}{ }^{2+}$ ion being $0.2 \AA$ smaller than the $\mathrm{U}^{4+}$ ion. ${ }^{60}$ This suggests the multiple bond character in the $\mathrm{U}=\mathrm{C}$ bond in $\mathbf{3 3}$ is much less pronounced than in the $\mathrm{U}^{\mathrm{IV}}-\mathrm{SCS}$ analogues 22, 24 and $\mathbf{2 8}$, which is attributed to the strong oxo bonding in the linear $\left\{\mathrm{UO}_{2}\right\}^{2+}$ uranyl dication unit. 


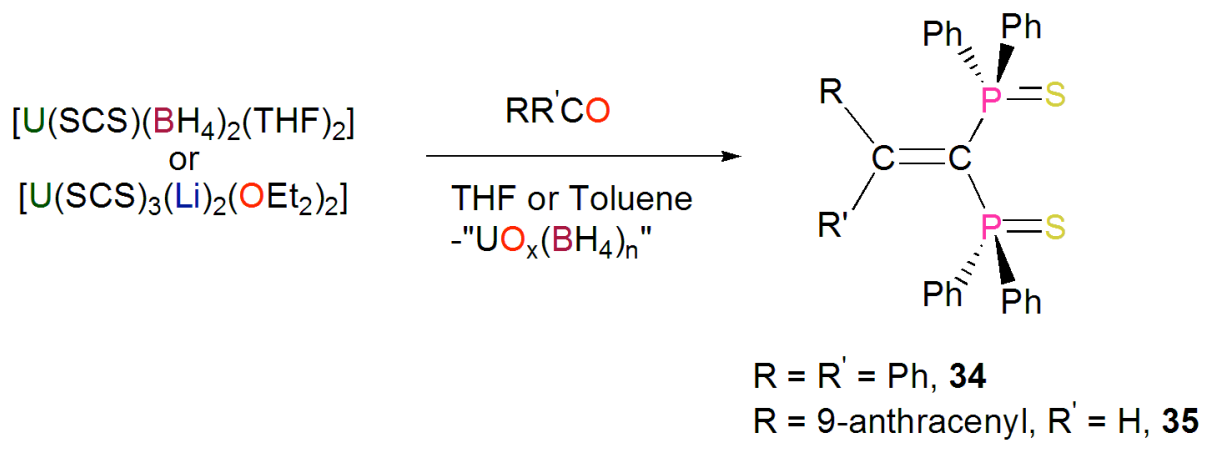

Scheme 13. Reactivity of 22-23.

Despite a significant number of reports of $\{\mathrm{SCS}\}^{2-}$ derived uranium carbenes, only limited reactivity studies have been reported. The reaction of $\mathbf{2 2}$ or $\mathbf{2 3}$ with either benzophenone or 9anthracene carboxaldehyde afford the corresponding Wittig-type alkene product $(\mathrm{R})\left(\mathrm{R}^{\prime}\right) \mathrm{C}=\mathrm{C}\left(\mathrm{PPh}_{2} \mathrm{~S}\right)_{2},\left(\mathrm{R}=\mathrm{R}^{\prime}=\mathrm{Ph}, 34 ; \mathrm{R}=9\right.$-anthracenyl, $\left.\mathrm{R}^{\prime}=\mathrm{H}, 35\right)$, respectively (Scheme 13). ${ }^{55}$ These reactions proceeded very rapidly, and it was not possible to trap any intermediate reaction products, as was possible for analogous rare earth reactivity studies. ${ }^{61,62}$

\section{Bis-Iminophosphorano-Stabilised Uranium Carbenes}

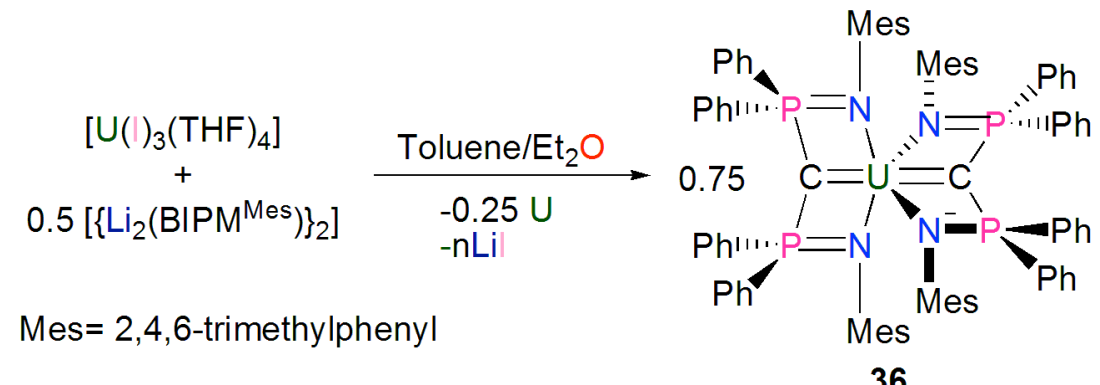

Scheme 14. Synthesis of 36.

The first example of a uranium carbene complex utilising a $\mathrm{BIPM}^{\mathrm{R}}$ ligand was reported by Liddle in 2010, with reaction of $\left[\mathrm{U}(\mathrm{I})_{3}(\mathrm{THF})_{4}\right]$ with half a molar equivalent of $\left[\left\{\mathrm{Li}_{2}\left(\mathrm{BIPM} \mathrm{Mes}^{\mathrm{Mes}}\right\}_{2}\right]\right.$. This afforded the homoleptic bis-carbene complex $\left[\mathrm{U}\left(\mathrm{BIPM}^{\mathrm{Mes}}\right)_{2}\right](\mathbf{3 6})$ by 
a disproportionation reaction and elimination of elemental uranium metal (Scheme 14). ${ }^{63}$ The structure of $\mathbf{3 6}$ exhibits a mean $\mathrm{U}=\mathrm{C}$ bond distance of $2.438(9) \AA$, which is at the higher end of the $\mathrm{U}=\mathrm{C}$ double bond range, but it is consistent with bond distances observed in the previously discussed U(SCS) carbene complexes. A DFT study of 36 revealed $\sigma$ - and $\pi$ bonding interactions, albeit polarised, between the two carbene centres and uranium.

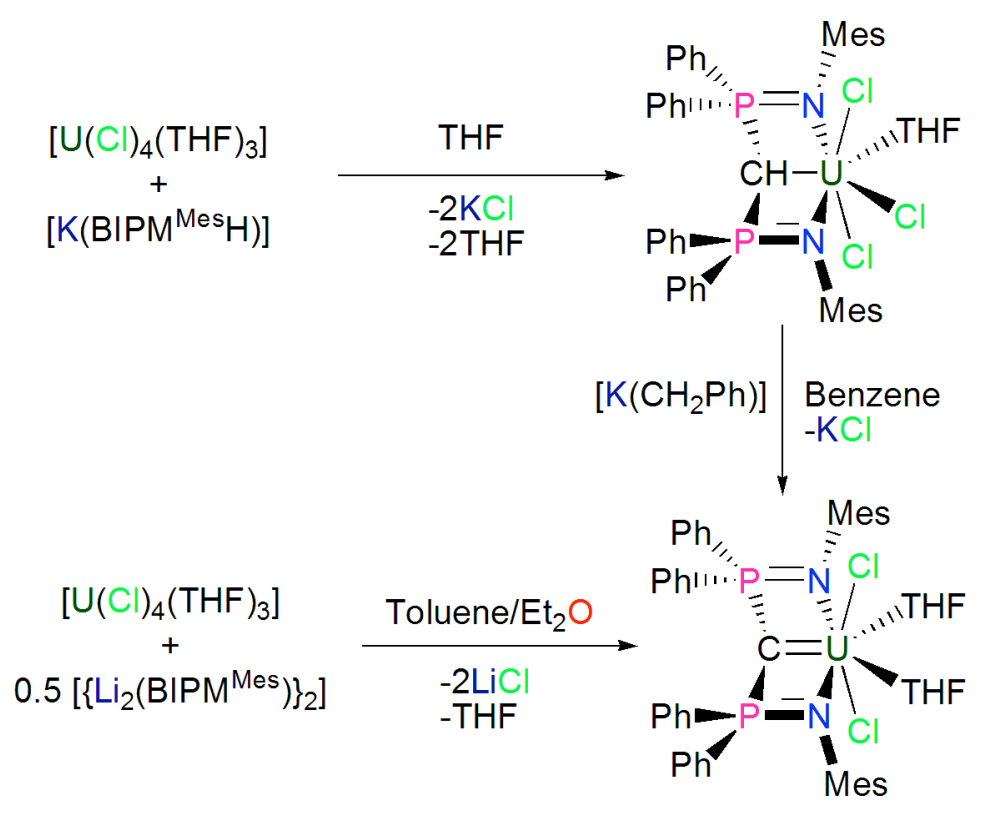

37

Scheme 15. Synthesis of 37.

The chemistry of uranium BIPM ${ }^{\mathrm{Mes}}$ complexes was further extended by the preparation of the mono-carbene $\left[\mathrm{U}\left(\mathrm{BIPM}^{\mathrm{Mes}}\right)(\mathrm{Cl})_{2}(\mathrm{THF})_{2}\right](37)$, which could be prepared via two routes (Scheme 15). ${ }^{64}$ Stepwise reaction with the preparation of the methanide $\left[\mathrm{U}\left(\mathrm{BIPM}^{\mathrm{Mes}} \mathrm{H}\right)(\mathrm{Cl})_{3}(\mathrm{THF})\right]$ from the reaction of $\left[\mathrm{U}(\mathrm{Cl})_{4}(\mathrm{THF})_{3}\right]$ with $\left[\mathrm{K}\left(\mathrm{BIPM}^{\mathrm{Mes}} \mathrm{H}\right)\right]$, followed by treatment with benzyl potassium to afford $37 .{ }^{64}$ It is of note that the preparation of $\left[\mathrm{U}\left(\mathrm{BIPM}{ }^{\mathrm{Mes}} \mathrm{H}\right)(\mathrm{Cl})_{3}(\mathrm{THF})\right]$ was straightforward, because related rare earth $\left\{\mathrm{BIPM}^{\mathrm{R}} \mathrm{H}\right\}^{-}$ methanide complexes require more esoteric ligand transfer reagents. ${ }^{65-68}$ Although this preparation could be achieved on a small scale, attempts to scale-up were capricious and it was reported that a more convenient synthetic route to 37 is from the reaction of 
$\left[\mathrm{U}(\mathrm{Cl})_{4}(\mathrm{THF})_{3}\right]$ with half an equivalent of $\left[\left\{\mathrm{Li}_{2}\left(\mathrm{BIPM}^{\mathrm{Mes}}\right)\right\}_{2}\right]$ with elimination of two equivalents of $\mathrm{LiCl}$. The $\mathrm{U}=\mathrm{C}$ distance in $\mathbf{3 7}$ of 2.358(4) $\AA$ is shorter than the $\mathrm{U}=\mathrm{C}$ distances in 36, as expected due to the decreased steric demands about uranium, and is in-line with the analogous $\{\mathrm{SCS}\}^{2-}$ complexes $\mathbf{2 4}$ and $\mathbf{2 2}$.

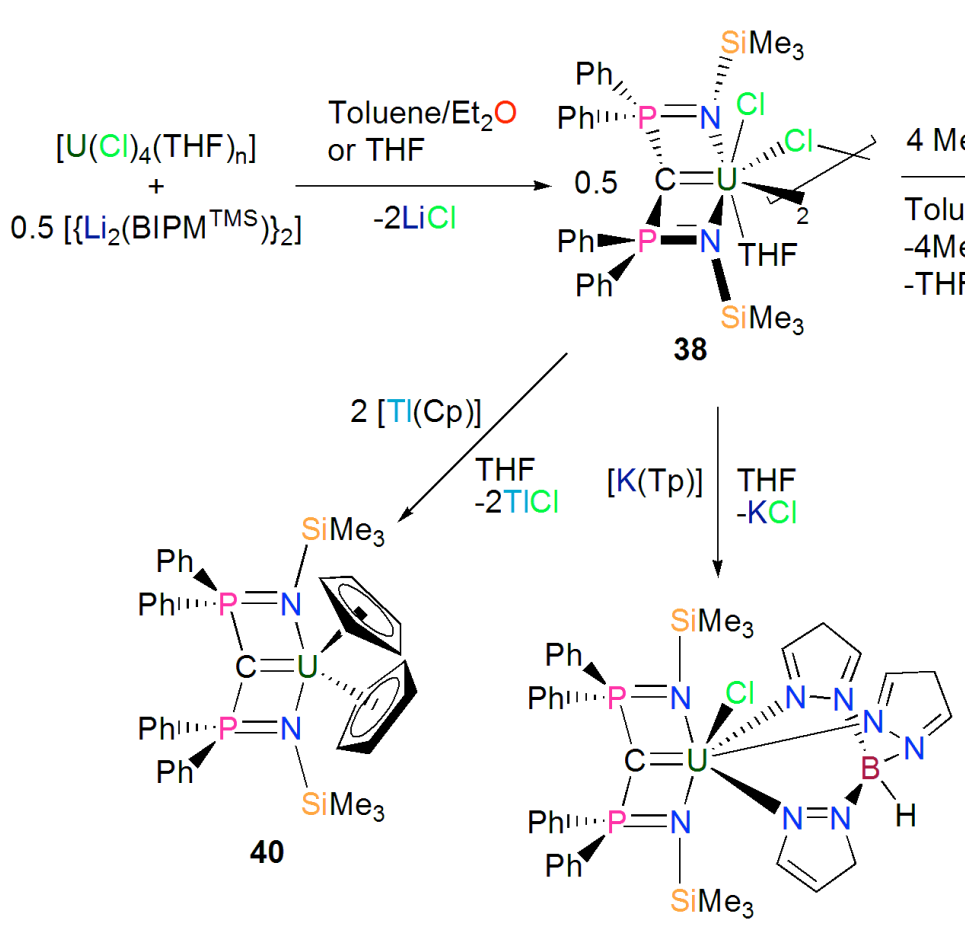

41
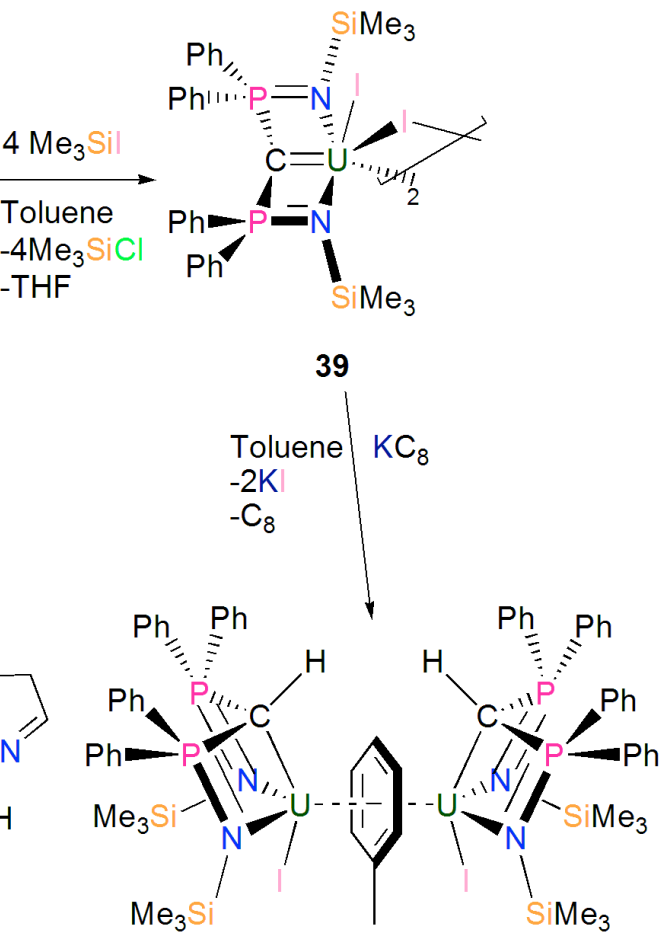

42

Scheme 16. Synthesis of 38-42.

The preparations of $\left\{\mathrm{BIPM}^{\mathrm{TMS}}\right\}^{2-}$ derived uranium carbenes were reported concurrently by Cavell and Liddle, ${ }^{69,70}$ who each reported that the reaction of $\mathrm{UCl}_{4} \mathrm{THF}_{\mathrm{n}}$ with half an equivalent of $\left.\left[\left\{\mathrm{Li}_{2} \mathrm{BIPM}^{\mathrm{TMS}}\right)\right\}_{2}\right]$ afforded the carbene complex $\left[\left\{\mathrm{U}\left(\mathrm{BIPM}^{\mathrm{TMS}}\right)(\mathrm{Cl})(\mathrm{THF})(\mu-\right.\right.$ $\mathrm{Cl})\}_{2}$ ] (38), following crystallisation from toluene (Scheme 16). ${ }^{69,70}$ Cavell was unable to structurally characterise $\mathbf{3 8}$, which they assumed to be monomeric solvent-free $\left[\mathrm{U}\left(\mathrm{BIPM}^{\mathrm{TMS}}\right)(\mathrm{Cl})_{2}\right],{ }^{70}$ however Liddle was able to confirm that the structure of $\mathbf{3 8}$ was in fact a solvated dinuclear complex in the solid state. ${ }^{69}$ Addition of four equivalents of 
trimethylsilyl iodide to $\mathbf{3 8}$ resulted in complete halide exchange yielding the iodide substituted carbene $\left[\left\{\mathrm{U}\left(\mathrm{BIPM}{ }^{\mathrm{TMS}}\right)(\mathrm{I})(\mu-\mathrm{I})\right\}_{2}\right](\mathbf{3 9})$ (Scheme 16). ${ }^{69}$ Structural characterisation of 38 and 39 revealed the $\mathrm{U}=\mathrm{C}$ bond distances in each complex to be statistically indistinguishable [38: 2.322(4) $\AA$; 39: 2.368(17) $\AA$ ] despite the variation in halide coordinated to the metal centre ${ }^{69}$ Cavell reported the derivitisation of $\mathbf{3 8}$ by reaction with two equivalents of $[\mathrm{Tl}(\mathrm{Cp})]$, or one equivalent of $[\mathrm{K}(\mathrm{Tp})](\mathrm{Tp}=\operatorname{tris}($ pyrazoyl)borate), to afford $\left[\mathrm{U}\left(\mathrm{BIPM}^{\mathrm{TMS}}\right)(\mathrm{Cp})_{2}\right] \quad(\mathbf{4 0})$ and $\left[\mathrm{U}\left(\mathrm{BIPM}^{\mathrm{TMS}}\right)(\mathrm{Tp})(\mathrm{Cl})\right]$ (41), respectively, (Scheme 16). Complexes 40 and 41 were structurally characterised, and found to exhibit $\mathrm{U}=\mathrm{C}$ bond distances of 2.351(2) and 2.376(3) $\AA$, respectively, which are each slightly longer than the $\mathrm{U}=\mathrm{C}$ bond distance reported for $\mathbf{3 8}^{70}$ Liddle then targeted the $\mathrm{U}^{\mathrm{III}}$ carbene $\left[\mathrm{U}\left(\mathrm{BIPM}^{\mathrm{TMS}}\right)(\mathrm{I})(\mathrm{THF})_{\mathrm{n}}\right]$, which would allow direct structural comparisons to rare earth analogues to be made, ${ }^{71}$ via the reduction of the $\mathrm{U}^{\mathrm{IV}}$ centre of $\mathbf{3 9}$ with $\mathrm{KC}_{8}$. However, this reaction did not proceed as anticipated. The product of the reaction was found to be the diuranium(III) methanide inverse sandwich complex $\left.\left[\left\{\mathrm{U}_{(\mathrm{BIPM}}{ }^{\mathrm{TMS}} \mathrm{H}\right)(\mathrm{I})\right\}_{2}\left(\mu-\mathrm{C}_{7} \mathrm{H}_{8}\right)\right]$ (42), via the reduction of the toluene solvent (Scheme 16). ${ }^{69}$ Magnetic investigations into $\mathbf{4 2}$ revealed that it exhibits single molecule magnetic behaviour. ${ }^{69}$ The ongoing absence of a uranium(III) carbene in this context is certainly in-line with the nucleophilic and hard nature of these carbenes, and suggests that the synthesis of such a low valent uranium carbene poses significant synthetic challenges. 


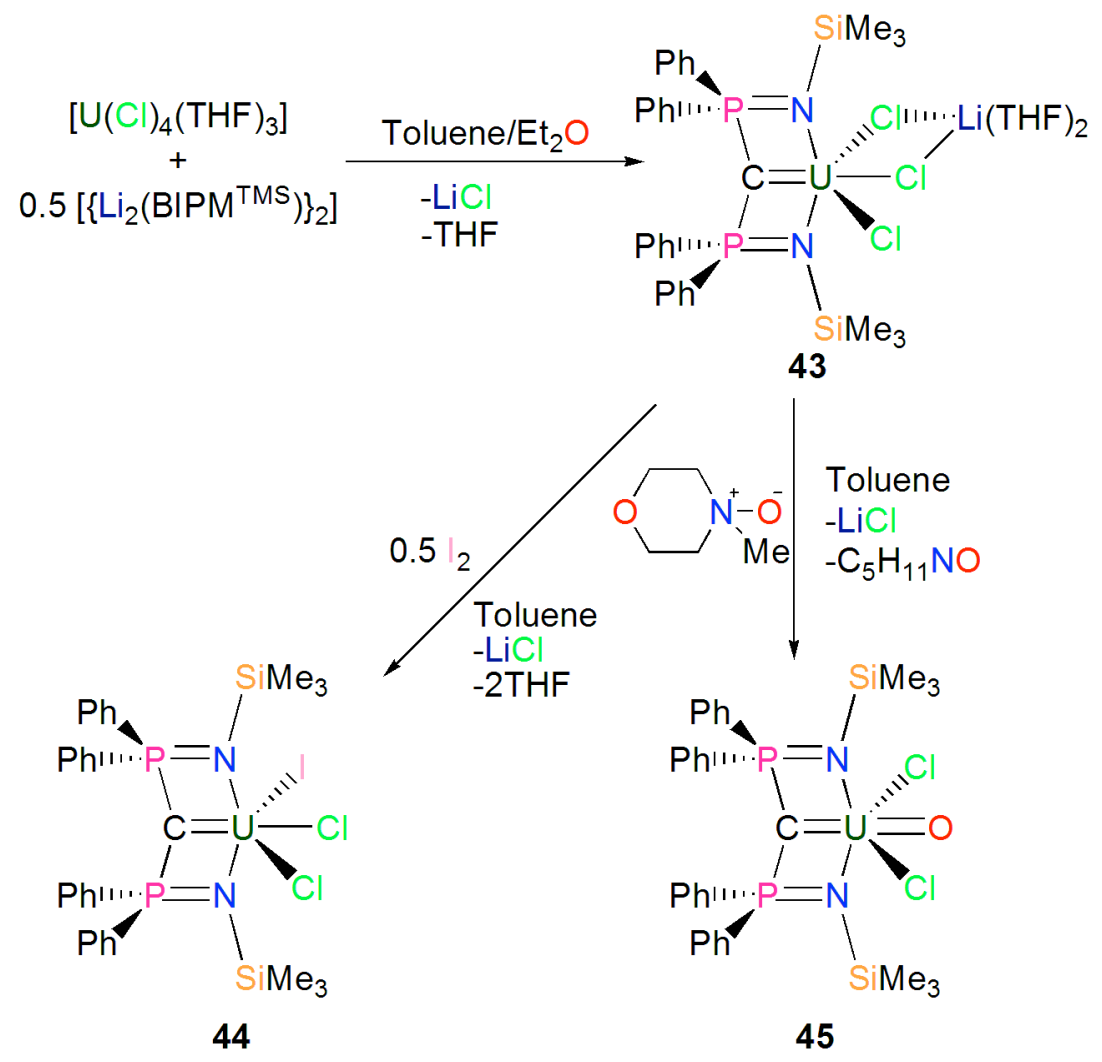

Scheme 17. Synthesis of 43-45.

Liddle reported an alternate synthetic route towards a mono-carbene $\left\{\mathrm{BIPM}^{\mathrm{TMS}}\right\}^{2-}$ uranium species, namely $\left[\mathrm{U}\left(\mathrm{BIPM}^{\mathrm{TMS}}\right)(\mathrm{Cl})(\mu-\mathrm{Cl})_{2}\left\{\mathrm{Li}(\mathrm{THF})_{2}\right\}\right] \quad$ (43), (Scheme 17). ${ }^{72}$ This was prepared in a similar manner to $\mathbf{3 8}$, but work-up is performed in THF rather than toluene, which gives a monomeric lithium chloride occluded species. The reaction of $\mathbf{4 3}$ with half an equivalent of elemental iodine resulted in oxidation of uranium to afford the mixed halide $\mathrm{U}^{\mathrm{V} \text { - }}$ carbene complex $\left[\mathrm{U}\left(\mathrm{BIPM}^{\mathrm{TMS}}\right)(\mathrm{Cl})_{2}(\mathrm{I})\right](\mathbf{4 4})$, which was the first example of a covalent uranium carbene complex not exhibiting a $\mathrm{U}^{\mathrm{IV}}$ centre in $c a .30$ years. ${ }^{72}$ Conversely to the aforementioned difficulties in obtaining a uranium(III) carbene, the oxidation of $\mathbf{4 3}$ by iodine is straightforward, confirming that such carbenes are effective at stabilising high oxidation state metals. Alternatively, treatment of $\mathbf{4 3}$ with 4-morpholine- $\mathrm{N}$-oxide resulted in a two electron oxidation yielding the $\mathrm{U}^{\mathrm{VI}}$ carbene mono-oxo complex $\left[\mathrm{U}\left(\mathrm{BIPM}^{\mathrm{TMS}}\right)(\mathrm{O})(\mathrm{Cl})_{2}\right](\mathbf{4 5})$ (Scheme 17). ${ }^{73}$ Structural and computational investigations into $\mathbf{4 5}$ reveal the oxo to be trans 
to the carbene carbon which bears all of the hallmarks of the inverse trans influence (ITI). ${ }^{74-81}$ The ITI is due to the semi-core $6 p_{z}$ orbital of uranium mixing with the $5 f$ orbitals leading to a hole in the $6 p_{z}$ orbital directed to the trans position of the strong oxo ligand. In the case of $\mathbf{4 5}$ the carbene centre is a stronger donor than the chlorides and can compensate for this hole more and so occupies the trans position to the oxo group. ${ }^{74}$ The $\mathrm{U}=\mathrm{C}$ bond distances of $\mathbf{4 3}, \mathbf{4 4}$ and 45 are $2.310(4), 2.268(10)$ and $2.184(3) \AA$, respectively, with the $\mathrm{U}=\mathrm{C}$ bond distance in 45 being the shortest $\mathrm{U}-\mathrm{C}$ bond distance on record. This can be attributed to the decreased ionic radius of $\mathrm{U}^{\mathrm{VI}}(0.73 \AA, 6$-coordinate $) v_{s} \mathrm{U}^{\mathrm{V}}(0.76 \AA$, 6-coordinate $)$ and $\mathrm{U}^{\mathrm{IV}}(0.89 \AA, 6$ coordinate), and perhaps also to the ITI. ${ }^{82}$ The structural similarity of 43-45 (two axial halides, meridionally coordinated carbene) renders them excellent candidates for a meaningful assessment of the impact of the oxidation state of uranium on the nature of the $\mathrm{U}=\mathrm{C}$ bond (see below) and combined DFT, NBO, and QTAIM studies are all consistent with the presence of polarised $\mathrm{U}=\mathrm{C}$ double bonds. 


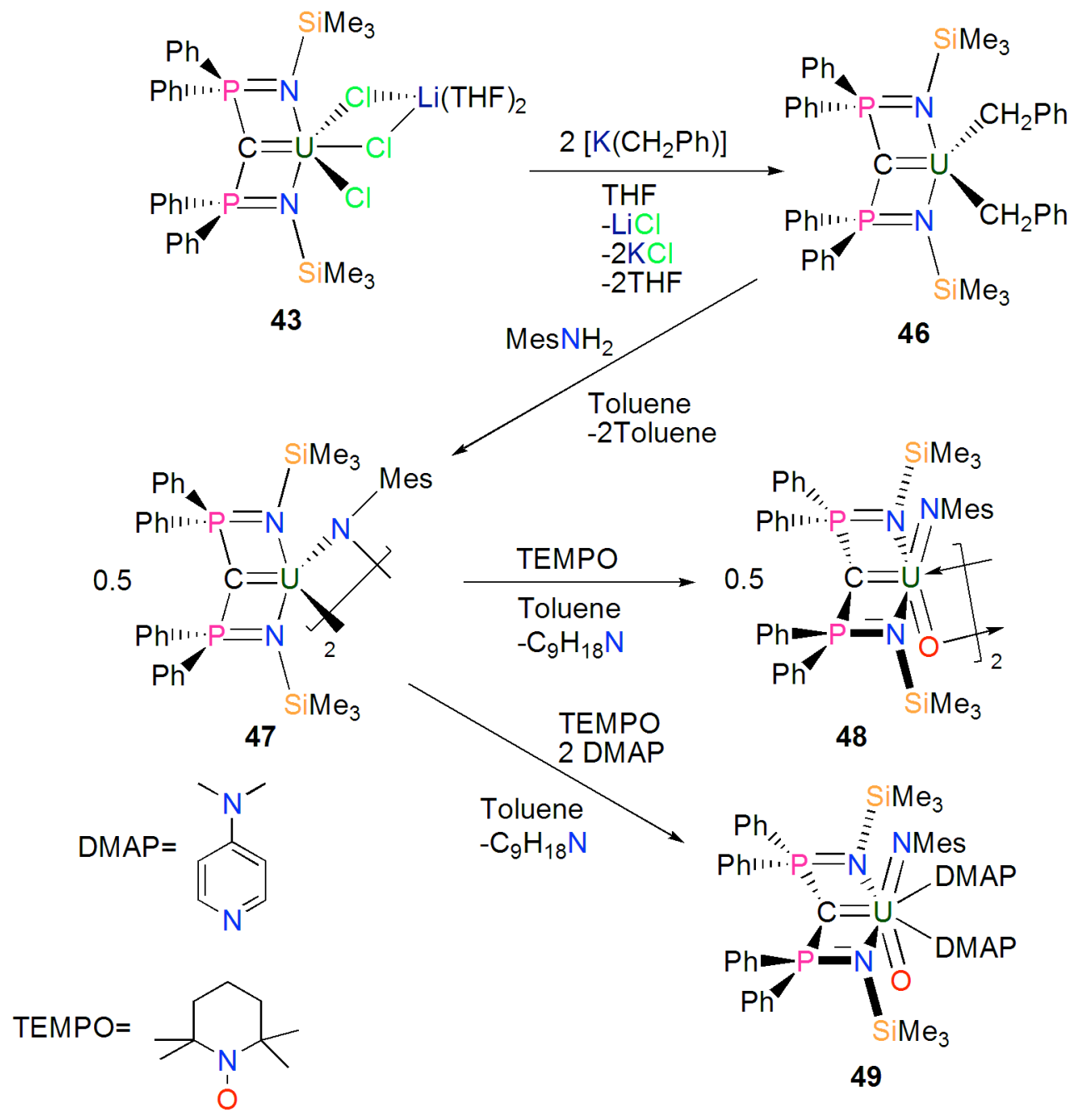

Scheme 18. Synthesis of 46-49.

The reaction of $\mathbf{4 3}$ with two equivalents of benzyl potassium afforded $\left[\mathrm{U}\left(\mathrm{BIPM}{ }^{\mathrm{TMS}}\right)\left(\mathrm{CH}_{2} \mathrm{Ph}\right)_{2}\right]$ (46), which was the first example of a dialkyl uranium carbene, (Scheme 18). ${ }^{83}$ Treatment of $\mathbf{4 6}$ with mesitylamine afforded the bridging uranium carbene imido complex $\left[\left\{\mathrm{U}\left(\mathrm{BIPM}^{\mathrm{TMS}}\right)(\mu-\mathrm{NMes})\right\}_{2}\right](47)$, via a double deprotonation of the amine with elimination of two equivalents of toluene (Scheme 18). Treatment of $\mathbf{4 7}$ with the oxygen transfer reagent tetramethylpiperidine- $N$-oxide (TEMPO) afforded the uranium carbene imido oxo complex $\left[\left\{\mathrm{U}\left(\mathrm{BIPM}^{\mathrm{TMS}}\right)(\mathrm{NMes})(\mu-\mathrm{O})\right\}_{2}\right](\mathbf{4 8})$, as a dinuclear species where the two oxos bridge the two uranium centres. Performing the reaction in the presence of two equivalents of 4-dimethylaminopyridine (DMAP), or alternately addition of two equivalents of DMAP to 
48, affords the mononuclear carbene imido oxo complex [U(BIPM $\left.\left.{ }^{\mathrm{TMS}}\right)(\mathrm{NMes})(\mathrm{O})(\mathrm{DMAP})_{2}\right]$ (49) (Scheme 18). ${ }^{83}$ Complex 49 is the first actinide complex to formally contain three multiply bonded ligands of three different elements, and structural characterisation revealed the imido and oxo- ligands to be mutually trans. This is in contrast to 45 where the carbene centre is trans to the oxo group, ${ }^{73}$ but is in line with the ITI, as it is more energetically favourable for the stronger imide donor to be trans to the oxo, rather than the carbene, which is a comparatively weaker donor. ${ }^{83}$ The $\mathrm{U}=\mathrm{C}$ bond distance in 49 [2.400(3) $\AA$ ] is over $0.2 \AA$ longer than the corresponding distance in $\mathbf{4 5}$ reflecting the robust $\{\mathrm{RNUO}\}^{2+}$ unit, but is still $\sim 0.1 \AA$ shorter than a U-C single bond and similar to the distance observed in the related uranyl $\{\mathrm{SCS}\}^{2-}$ carbene $33 .{ }^{59} \mathrm{~A}$ DFT, NBO, and QTAIM study of 49 found that whilst the oxo and imido groups exhibit triple bonding interactions to uranium, the carbene, although presenting a double bond combination, presents a highly polarised bonding interaction to uranium. 

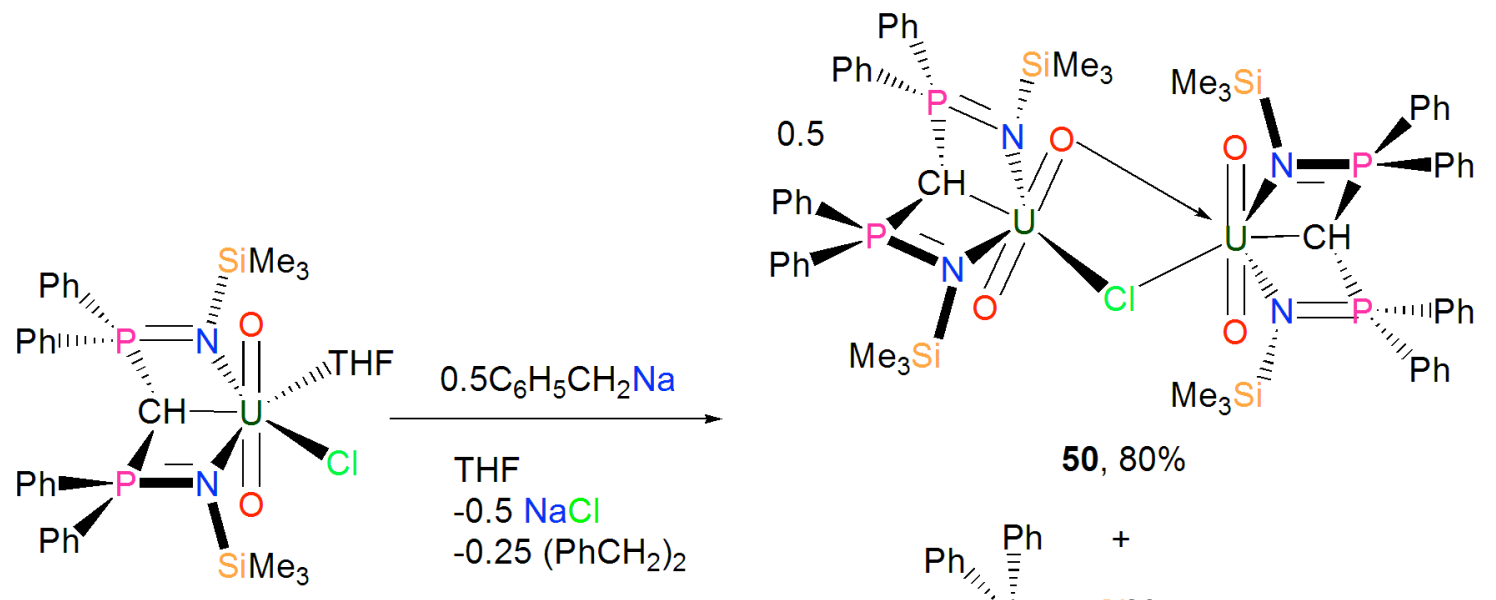

$50,80 \%$

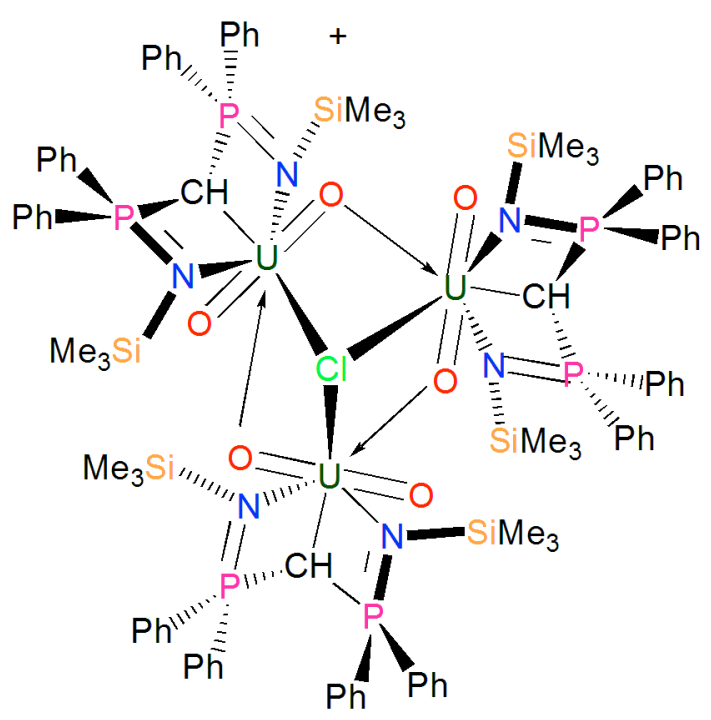

$51,2 \%$

Scheme 19. Synthesis of 50-51.

Although the $\left\{\mathrm{BIPM}^{\mathrm{TMS}}\right\}^{2-}$ ligand had been utilised in the preparation of $\mathrm{U}^{\mathrm{IV}}, \mathrm{U}^{\mathrm{V}}$, and nonuranyl $\mathrm{U}^{\mathrm{VI}} \mathrm{U}=\mathrm{C}$ complexes, an analogue of $\mathbf{3 3}$ remained a synthetic target. Investigations began with ascertaining whether the deprotonation of $\left[\mathrm{U}\left(\mathrm{BIPM}^{\mathrm{TMS}} \mathrm{H}\right)(\mathrm{O})_{2}(\mathrm{Cl})(\mathrm{THF})\right]$ with a suitable base, such as benzyl sodium would afford the uranyl carbene $\left[\mathrm{U}\left(\mathrm{BIPM}^{\mathrm{TMS}}\right)(\mathrm{O})_{2}(\mathrm{THF})_{\mathrm{n}}\right]$ via elimination of sodium chloride and toluene, in an analogous fashion to rare earth systems. ${ }^{68,84,85}$ However a uranyl carbene was not isolated, and instead the mixed valence dinuclear methanide $U^{\mathrm{V}}-\mathrm{U}^{\mathrm{VI}}$ complex $\left[\left\{\mathrm{U}\left(\mathrm{BIPM}^{\mathrm{TMS}} \mathrm{H}\right)(\mathrm{O})_{2}\right\}_{2}(\mu-\mathrm{Cl})\right], \mathbf{5 0}$, was observed as the major reaction product, with the $\mathrm{U}^{\mathrm{V}-} \mathrm{U}^{\mathrm{V}}-\mathrm{U}^{\mathrm{VI}}$ trimetallic $\left[\left\{\mathrm{U}\left(\mathrm{BIPM}{ }^{\mathrm{TMS}} \mathrm{H}\right)(\mathrm{O})_{2}\right\}_{3}\left(\mu^{3}-\mathrm{Cl}\right)\right], \mathbf{5 1}$, also observed as a minor product (Scheme 19). ${ }^{73}$ The formation of these complexes, which are the first examples of organometallic uranyl(V) 
complexes, was somewhat unexpected, given the straightforward preparation of $\mathbf{3 3}$, but it is in-line with the reducing nature of alkali metal alkyls. ${ }^{86-88}$

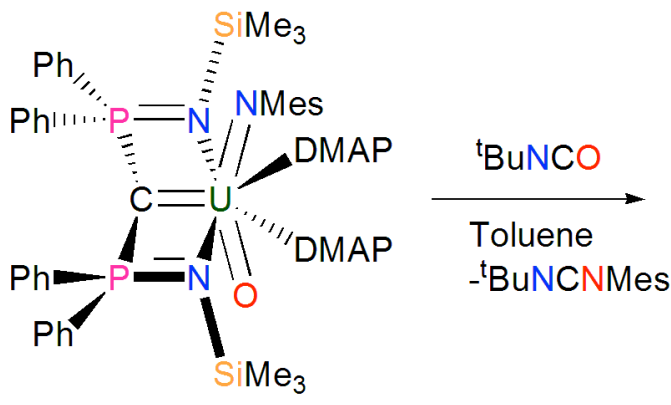

49

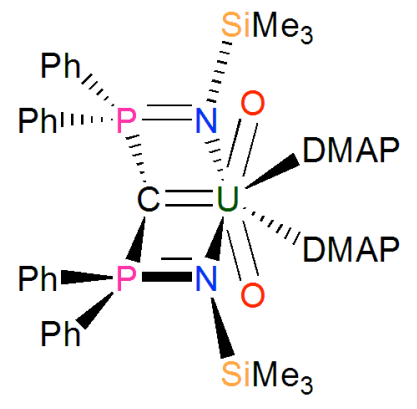

52

Scheme 20. Synthesis of 52.

Following the failed attempts to prepare a uranyl carbene from the deprotonation of a $\left\{\mathrm{BIPM}^{\mathrm{TMS}} \mathrm{H}\right\}^{-}$uranium methanide precursor, an alternative strategy was employed. It was found that the metathesis reaction of 49 with tert-butylisocyanate afforded $\left[\mathrm{U}\left(\mathrm{BIPM}^{\mathrm{TMS}}\right)(\mathrm{O})_{2}(\mathrm{DMAP})_{2}\right](\mathbf{5 2})($ Scheme 20$) .{ }^{83}$ The strucutre of 52 exhibits a $\mathrm{U}=\mathrm{C}$ distance of 2.383(3) $\AA$, which is similar to the analogous distances in $\mathbf{3 3}$ and $\mathbf{4 9}$. 


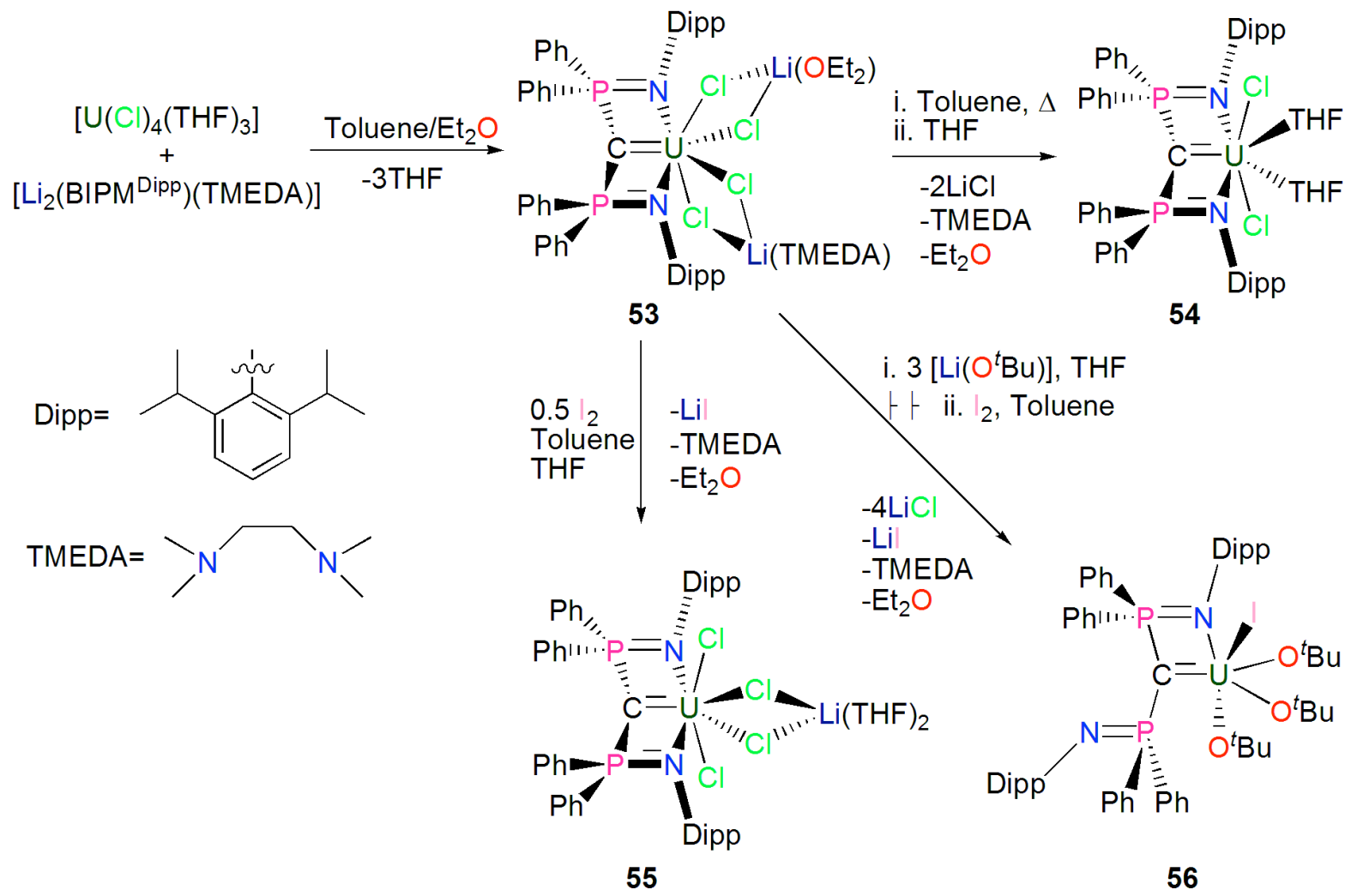

Scheme 21. Synthesis of 53-56.

The 2,6-diisopropylphenyl (Dipp) substituted BIPM ligand $\left\{\mathrm{BIPM}^{\mathrm{Dipp}}\right\}^{2-}$ has also been employed in the preparation of uranium carbene complexes. The reaction of $\left[\mathrm{U}(\mathrm{Cl})_{4}(\mathrm{THF})_{3}\right]$ with $\left[\mathrm{Li}_{2}\left(\mathrm{BIPM}^{\mathrm{Dipp}}\right)(\mathrm{TMEDA})\right]$, which was found to exhibit an unusual trans-planar four coordinate carbon centre, ${ }^{89}$ afforded the carbene complex $\left[\mathrm{U}\left(\mathrm{BIPM}^{\mathrm{Dipp}}\right)(\mu-\mathrm{Cl})_{2}\left\{\mathrm{Li}\left(\mathrm{OEt}_{2}\right)\right\}(\mu-\right.$ $\left.\mathrm{Cl})_{2}\{\operatorname{Li}(\mathrm{TMEDA})\}\right](\mathbf{5 3})$ as a lithium chloride occluded complex (Scheme 21$) .{ }^{64}$ The lithium chloride-free product $\left[\mathrm{U}\left(\mathrm{BIPM}^{\mathrm{Dipp}}\right)(\mathrm{Cl})_{2}(\mathrm{THF})_{2}\right](\mathbf{5 4})$ could be prepared by refluxing $\mathbf{5 3}$ in toluene followed by crystallisation from THF. The reaction of $\mathbf{5 3}$ with half an equivalent of elemental iodine effected oxidation of uranium from $\mathrm{U}^{\mathrm{IV}}$ to $\mathrm{U}^{\mathrm{V}}$ yielding the carbene complex $\left[\mathrm{U}\left(\mathrm{BIPM}^{\mathrm{Dipp}}\right)(\mathrm{Cl})_{2}(\mu-\mathrm{Cl})_{2}\left\{\mathrm{Li}(\mathrm{THF})_{2}\right\}\right](\mathbf{5 5})($ Scheme 21$),{ }^{64}$ analogously to the preparation of 44 (Scheme 17). Alternatively, the reaction of 53 with three equivalents of lithium tertbutoxide followed by oxidation with one equivalent of elemental iodine affords the $\mathrm{U}^{\mathrm{VI}}$ carbene complex $\left[\mathrm{U}\left(\mathrm{BIPM}^{\mathrm{Dipp}}\right)\left(\mathrm{O}^{t} \mathrm{Bu}\right)_{3}(\mathrm{I})\right](\mathbf{5 6})($ Scheme 21$) .{ }^{64}$ Structural investigation of 56 
show one of the imino arms is pendant, and the $\mathrm{U}=\mathrm{C}$ bond distance of $2.449(7) \AA$ is over 0.2 $\AA$ longer than observed in $\mathbf{4 5}$, which could be a result of the increased steric congestion from the tert-butoxide ligands. Additionally, an increase in the interaction between the uranium and hard oxygen atoms could lead to a decrease in the interaction between the uranium and softer carbon. Attempts to prepare $\left\{\mathrm{BIPM}^{\mathrm{Dipp}}\right\}^{2-}$ derived analogues of the $\mathrm{U}^{\mathrm{VI}}$ carbene $\mathbf{4 5}$ were unsuccessful, with reactions of $\mathbf{5 3}$ with two electron oxidants such as morpholine- $N$ oxide, TEMPO, or pyridine- $N$-oxide, leading solely to uranyl methanide complexes. ${ }^{64}$
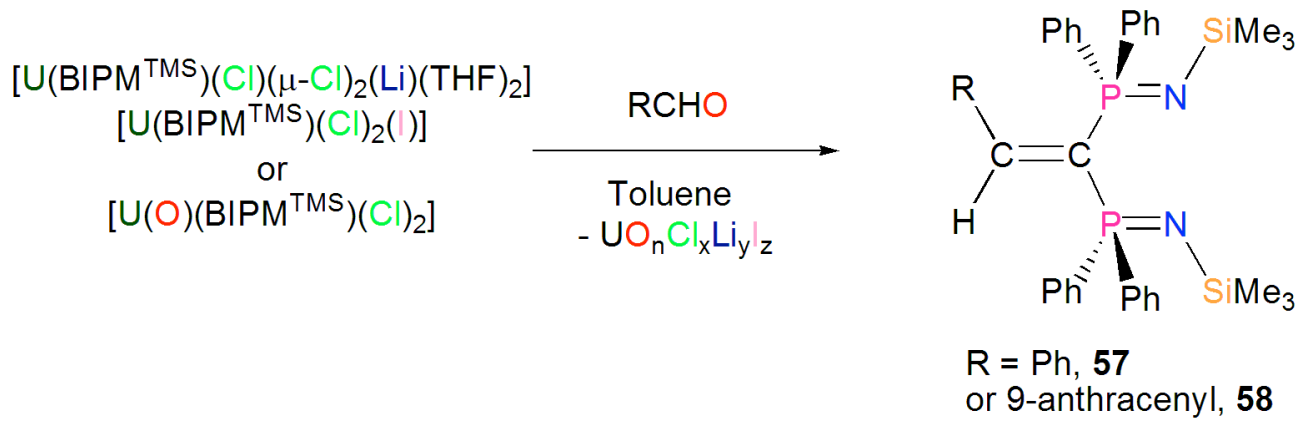

Scheme 22. Synthesis of 57-58.

The reactivity of $\left\{\mathrm{BIPM}^{\mathrm{R}}\right\}^{2-}$ uranium complexes has been well reported in recent years. Complexes 43-45 react with either benzaldehyde or 9-anthracene carboxaldehyde to afford the corresponding Wittig-type alkene product $(\mathrm{H})(\mathrm{R}) \mathrm{C}=\mathrm{C}\left(\mathrm{PPh}_{2} \mathrm{NSiMe}_{3}\right)_{2},(\mathrm{R}=\mathrm{Ph}, \mathbf{5 7} ; \mathrm{R}=9$ anthracenyl, 58) with concomitant elimination of uranyl dichloride by-products (Scheme 22). ${ }^{72,73,89}$ 


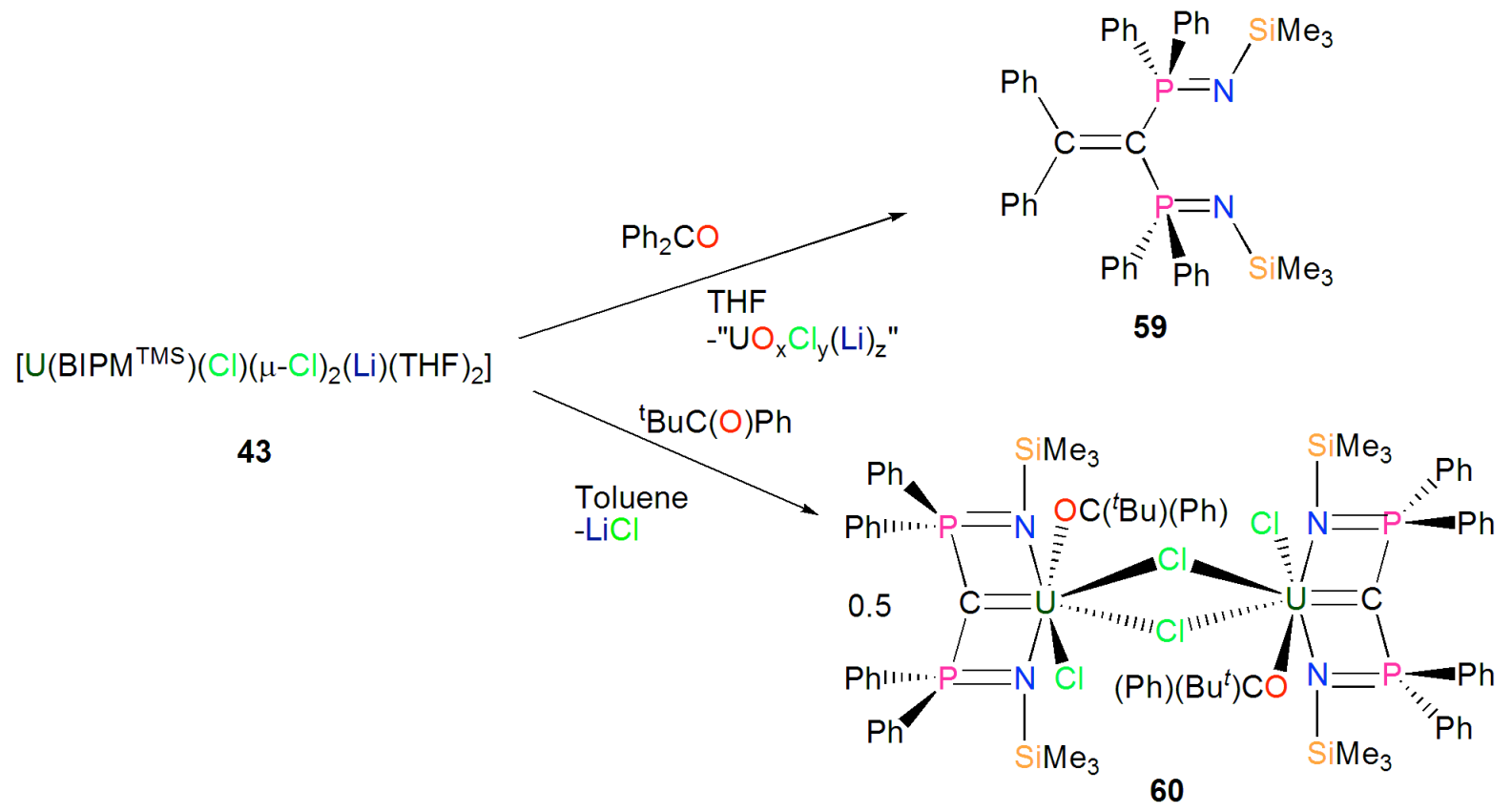

Scheme 23. Reactivity of 43.

The reactivity of $\mathbf{4 3}$ towards benzophenone was investigated, and the reaction yielded the Wittig-type alkene product $(\mathrm{Ph})_{2} \mathrm{C}=\mathrm{C}\left(\mathrm{PPh}_{2} \mathrm{NSiMe}_{3}\right)_{2}(\mathbf{5 9})($ Scheme 23$) .{ }^{90}$ The reaction of 43 with the more sterically demanding tert-butyl phenyl ketone did not afford the Wittig-type product $\left({ }^{t} \mathrm{Bu}\right)(\mathrm{Ph}) \mathrm{C}=\mathrm{C}\left(\mathrm{PPh}_{2} \mathrm{NSiMe}_{3}\right)_{2}$ as anticipated, but instead afforded the ketone adduct $\left[\left\{\mathrm{U}\left(\mathrm{BIPM}^{\mathrm{TMS}}\right)(\mathrm{Cl})\left[\mathrm{O}=\mathrm{C}(\mathrm{Ph})\left({ }^{t} \mathrm{Bu}\right)\right](\mu-\mathrm{Cl})\right\}_{2}\right] \quad(\mathbf{6 0})$ with elimination of lithium chloride (Scheme 23). ${ }^{90}$ Structural characterisation of $\mathbf{6 0}$ revealed the ketone to be coordinated to the uranium centre through the ketyl oxygen atom with two chloride atoms bridging two metal centres forming a dinuclear species. The lack of reactivity exhibited by $\mathbf{4 3}$ towards ${ }^{t} \mathrm{BuC}(\mathrm{O}) \mathrm{Ph}$ was attributed the more sterically demanding nature of the ketone preventing any Wittig-type reaction from occurring. ${ }^{90}$ 


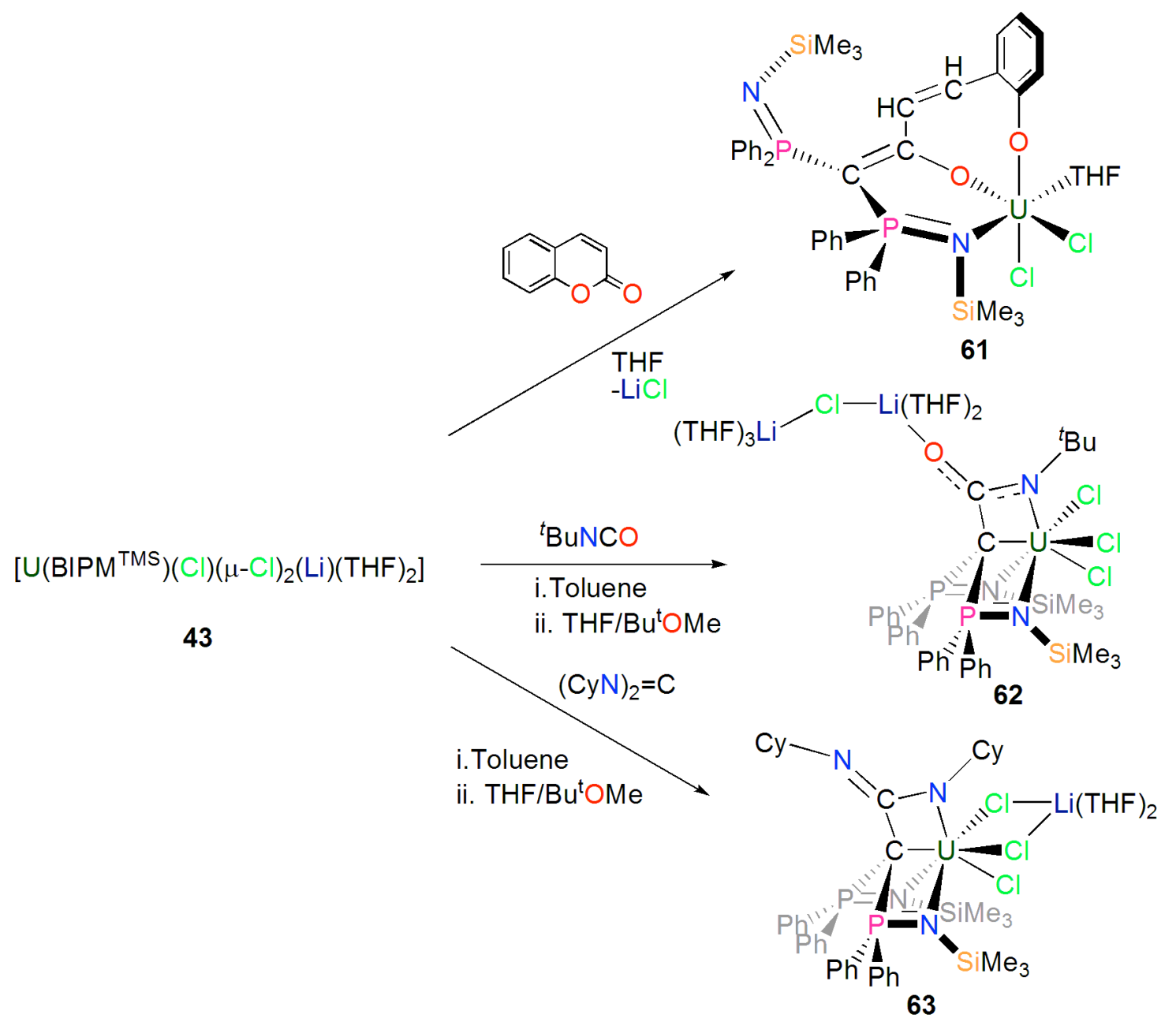

Scheme 24. Reactivity of 43.

The reactivity of $\mathbf{4 3}$ towards other unsaturated organic substrates has also been investigated. The reaction of $\mathbf{4 3}$ with coumarin afforded $\left[\mathrm{U}\left\{\mathrm{BIPM}^{\mathrm{TMS}}\left[\mathrm{C}(\mathrm{O})\left(\mathrm{CHCHC}_{6} \mathrm{H}_{4} \mathrm{O}-2\right\}(\mathrm{Cl})_{2}(\mathrm{THF})\right]\right.\right.$ (61), where nucleophilic attack of the ester carbon by the carbene has resulted in ring opening and the formation of an enolate and aryloxide (Scheme 24). ${ }^{90}$ The reaction of $\mathbf{4 3}$ with tertbutyl isocyanate and dicyclohexyl carbodiimide afforded $\left[\mathrm{U}\left\{\mathrm{BIPM}^{\mathrm{TMS}}\left[\mathrm{C}\left(\mathrm{N}^{t} \mathrm{Bu}\right)\left\{\mathrm{OLi}(\mathrm{THF})_{2}(\mu-\mathrm{Cl}) \mathrm{Li}(\mathrm{THF})_{3}\right\}\right]\right\}(\mathrm{Cl})_{3}\right]$ $\left[\mathrm{U}\left\{\mathrm{BIPM}^{\mathrm{TMS}}[\mathrm{C}(\mathrm{NCy}) 2]\right\}(\mathrm{Cl})(\mu-\mathrm{Cl})_{2} \mathrm{Li}(\mathrm{THF})_{2}\right](\mathbf{6 3})$, respectively, where the isocyanate and carbodiimide have undergone $[2+2]$ cycloaddition reactions across the $\mathrm{U}=\mathrm{C}$ double bond (Scheme 24). 


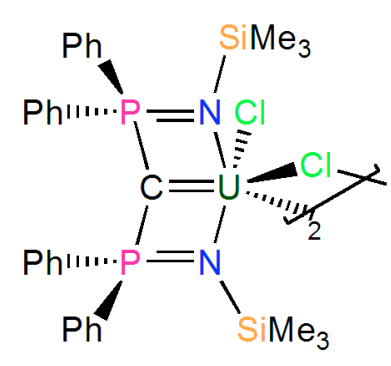

38

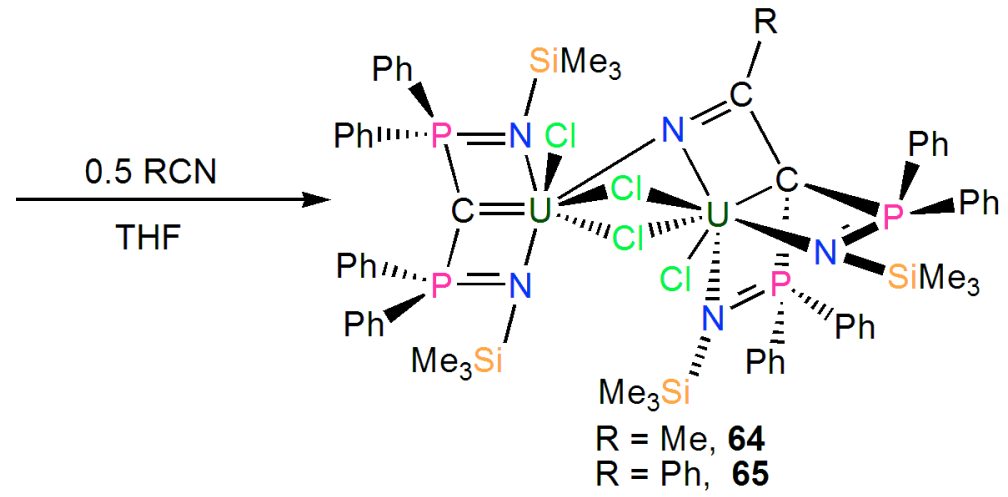

Scheme 25. Reactivity of 38 .

Cavell reported the reactivity of " $\left[\left\{\mathrm{U}\left(\mathrm{BIPM}^{\mathrm{TMS}}\right)(\mathrm{Cl})(\mu-\mathrm{Cl})\right\}_{2}\right]$ " towards benzonitrile and acetonitrile, which gave the $[2+2]$ cycloaddition products $\left[\left(\mathrm{BIPM}^{\mathrm{TMS}}\right)(\mathrm{Cl}) \mathrm{U}(\mu\right.$ $\left.\mathrm{Cl})_{2} \mathrm{UCl}\left\{\mathrm{NC}(\mathrm{R}) \mathrm{C}\left(\mathrm{PPh}_{2} \mathrm{NSiMe}_{3}\right)\right\}\right](\mathrm{R}=\mathrm{Me}, \mathbf{6 4} ; \mathrm{R}=\mathrm{Ph}, \mathbf{6 5}),($ Scheme 25$) .^{70}$ The U-C and $\mathrm{U}=\mathrm{C}$ bond distances of $64[2.660(7)$ and $2.337(7) \AA$ respectively] suggest the presence of methanide and methanediide centres. Despite addition of increased amounts of nitriles, only 64 or 65 were isolated, which could be due to coordination of the nitrile nitrogen to both uranium centres possibly blocking the coordination and reaction of other nitrile molecules.
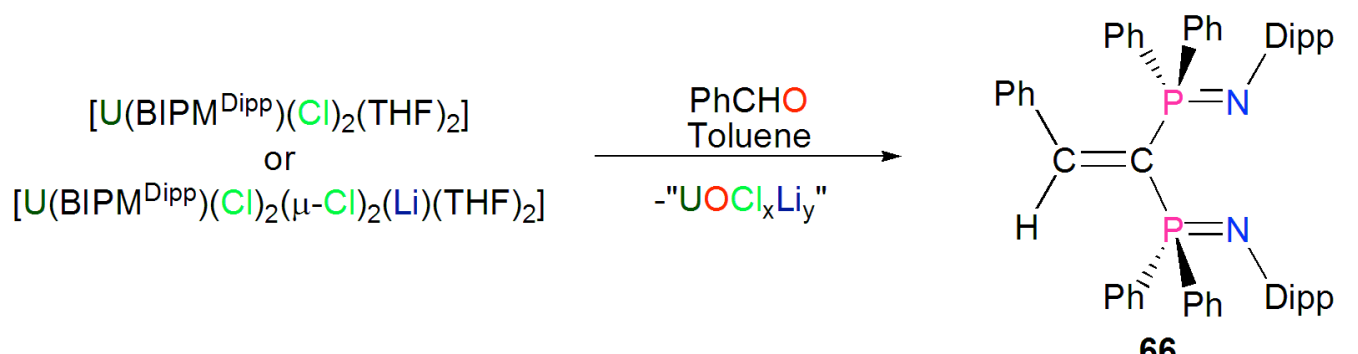

Scheme 26. Reactivity of 54-55.

Reactivity studies of uranium $\left\{\mathrm{BIPM}^{\mathrm{Dipp}}\right\}^{2-}$ carbenes have also been reported towards aldehydes and ketones (Scheme 26). The reaction of $\mathbf{5 4}$ or 55 with benzaldehyde afforded conversion to the Wittig-type alkene product $(\mathrm{H})(\mathrm{Ph}) \mathrm{C}=\mathrm{C}\left(\mathrm{PPh}_{2} \mathrm{NDipp}\right)_{2}(\mathbf{6 6})$, analogously to the reactivity observed by $\mathbf{4 3 - 4 5}$. 


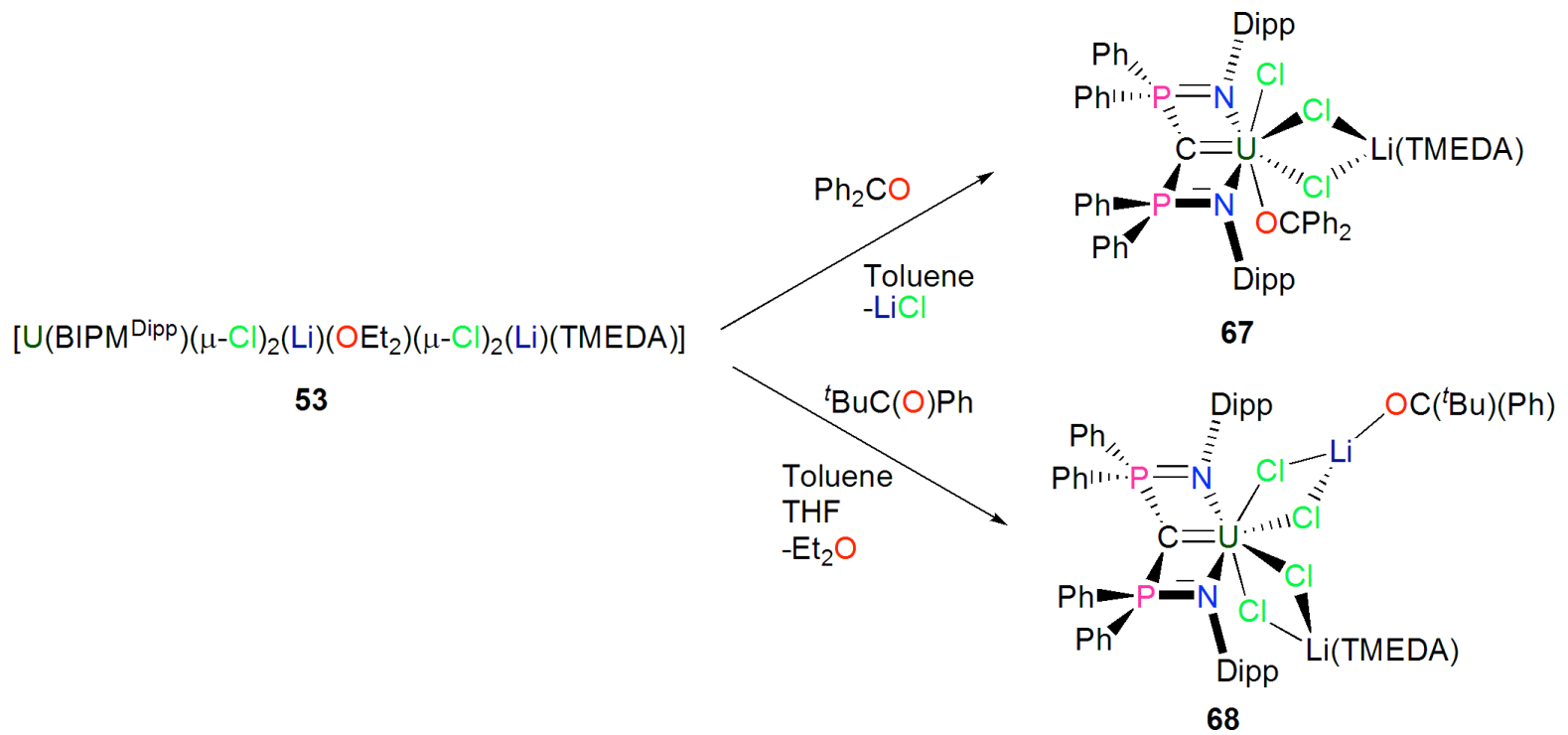

Scheme 27. Reactivity of 53.

In contrast to $\mathbf{4 3}$, the reaction of $\mathbf{5 3}$ with benzophenone or tert-butyl phenyl ketone afforded the coordinated ketone products $\left[\mathrm{U}\left(\mathrm{BIPM}^{\mathrm{Dipp}}\right)(\mathrm{Cl})\left(\mathrm{OCPh}_{2}\right)(\mu-\mathrm{Cl})_{2}\{\mathrm{Li}(\mathrm{TMEDA})\}\right](67)$ and $\left[\mathrm{U}\left(\mathrm{BIPM}^{\mathrm{Dipp}}\right)(\mu-\mathrm{Cl})_{2}\left\{\mathrm{Li}\left(\mathrm{OC}\left({ }^{t} \mathrm{Bu}\right)(\mathrm{Ph})\right\}(\mu-\mathrm{Cl})_{2}\{\mathrm{Li}(\mathrm{TMEDA})\}\right] \quad(\mathbf{6 8}), \quad\right.$ respectively, with coordination of the ketone to the uranium centre in the former and to the lithium centre in the latter (Scheme 27). ${ }^{64}$ It was reasoned that the occluded lithium chloride could be blocking the reactivity of the carbene, however when the reactions were repeated utilising the lithium chloride free carbene 54, no reactivity was observed. As a result, the lack of observed reactivity was attributed to the increased steric demands of the Dipp substituents in comparison to $\mathrm{SiMe}_{3}$.

\section{The Nature of the $U=C$ Bond}

As mentioned above, the classification of the $f$-block $\mathrm{M}=\mathrm{C}$ bond has proven controversial, with the carbon centres being described variously as methanediides, alkylidenes or carbenes. Due to the large variety of $\mathrm{U}=\mathrm{C}$ complexes reported in the last five years, it is now possible 
to compare and contrast the bonding in these complexes. Recently, Liddle investigated the nature of the bonding of these $\mathrm{U}=\mathrm{C}$ complexes via DFT studies, alongside suitable methanides and rare earth or transition metal complexes for comparison. ${ }^{64}$ Table 1 contains a summary of the calculated and experimental $\mathrm{M}=\mathrm{C}$ bond lengths and bond indices, contribution from the metal and carbon to the $\mathrm{M}=\mathrm{C}$ bond along with the orbitals involved in the bonding for a range of $\mathrm{M}=\mathrm{C}$ complexes. There was generally good agreement between calculated and experimentally observed bonding parameters so the models were determined to provide a qualitative and internally consistent description of the electronic structures of these complexes. ${ }^{64}$ The calculated Nalewajski-Mrozek bond indices for the $\mathrm{U}=\mathrm{C}$ bonds in the $\left\{\mathrm{BIPM}^{\mathrm{TMS}}\right\}^{2-} \mathrm{U}^{\mathrm{IV}}$ carbenes $\mathbf{3 7}, \mathbf{4 3}, \mathbf{5 3 - 5 4}$ range from $1.43-1.48$, which is $c a$. 0.1 higher than the $\{\mathrm{SCS}\}^{2-} \mathrm{U}^{\mathrm{IV}}$ carbenes 22, 24, 30 and 32 (range $1.26-1.34$ ), but are lower than the monophosporano carbenes 1 and 3 (1.64 and 1.66, respectively). It was found that $\mathrm{U}^{\mathrm{V}}=\mathrm{C}$ bonds have similar bond indices to $\mathrm{U}^{\mathrm{IV}}$ counterparts, but $\mathrm{U}^{\mathrm{VI}}=\mathrm{C}$ complexes show a range of bond indices, with 33 being at the lower end of the range (1.13) and 45 and 56 being at the high end of the range (1.5). These bond indices were compared to analogous rare earth and early transition metal complexes, and the $\mathrm{U}=\mathrm{C}$ carbenes exhibit much higher $\mathrm{M}=\mathrm{C}$ bond indices, with group 4 BIPM $\left.^{\mathrm{TMS}}\right\}^{2-}$ complexes ranging $0.93-1.04$ and rare earth(III) complexes 0.69 - 0.75. However, it should be noted that the only example of a rare earth(IV) covalent carbene, $\left[\mathrm{Ce}\left(\mathrm{BIPM}^{\mathrm{TMS}}\right)(\mathrm{ODipp})_{2}\right]$, was reported to have a $\mathrm{M}=\mathrm{C}$ bond index (1.1) which is approaching the levels of the uranium systems. ${ }^{68}$ It was calculated, however, that the $U=C$ systems do have lower bond indices than a typical Schrock type alkylkidene, namely $\left[\left(\mathrm{Bu}^{\mathrm{t}} \mathrm{CH}_{2}\right)_{3} \mathrm{Ta}=\mathrm{CHBu}^{\mathrm{t}}\right]$, which was found to have a $\mathrm{Ta}=\mathrm{C}$ bond index of 1.88 . The conclusion from this data is that whereas in rare earth methanediides the carbene charge is largely localised, for $\mathrm{U}=\mathrm{C}$ bonds the bonding is more akin to a double bond, but more polarised comapred to an archetypal Schrock alkylidene. 
In addition to the calculated Nalewajski-Mrozek bond indices, natural bond orbital (NBO) analyses were performed in order to determine the level of donation of electron density from the metal centre to the $\mathrm{M}=\mathrm{C}$ bond. The bonds were found to be highly polarised and ionic in nature, with the carbene donating more electron density to the $\mathrm{M}=\mathrm{C}$ bonds than the metal. It was found that for $\left\{\mathrm{BIPM}^{\mathrm{TMS}}\right\}^{2-}$ and $\{\mathrm{SCS}\}^{2-}$ systems the contribution from uranium to the $\sigma$ bond varies from 14 to $32 \%$ with increasing uranium contributions on increasing oxidation state, with the exception of $\mathbf{5 6}$, which exhibits essentially zero contribution from uranium into the $\sigma$-bond. This is attributed to only one imino group of $\left\{\mathrm{BIPM}^{\mathrm{TMS}}\right\}^{2-}$ being coordinated in 56, and is in agreement with $\mathbf{1}$ and $\mathbf{3}$ which also exhibit essentially zero contributions from the uranium centres to the $\sigma$ - components of the $\mathrm{U}=\mathrm{C}$ bonds. These values are found to be analogous to group four congeners, but in contrast to rare earth species, which exhibit essentially zero metal contribution to the $\mathrm{M}=\mathrm{C}$ bond. Contributions to the $\pi$-component of the $\mathrm{M}=\mathrm{C}$ bond are between $18-26 \%$ for $\left\{\mathrm{BIPM}^{\mathrm{TMS}}\right\}^{2-}$ complexes, which is slightly higher than for $\{\mathrm{SCS}\}^{2-}$ complexes $(9.3-15.8 \%)$, whilst $\mathbf{1}$ and $\mathbf{3}$ are towards the top end of this range (24.5 - 25.1). These values were found to be similar across the series and are independent of the amount of contribution found in the $\sigma$-bonding component, and are larger than thorium and rare earth analogues, which exhibit primarily ionic interactions, but lower than the $\mathrm{Ta}=\mathrm{C}$ complex $\left[\left(\mathrm{Bu}^{\mathrm{t}} \mathrm{CH}_{2}\right)_{3} \mathrm{Ta}=\mathrm{CHBu}^{t}\right]$, which exhibited $39 \%$ Ta character in the $\mathrm{Ta}=\mathrm{C} \pi$-bond. These results show that $\mathrm{U}=\mathrm{C}$ complexes, in particular higher oxidation state complexes, exhibit metal contributions which are almost comparable to levels exhibited by transition metal complexes. This enables the degree of covalency in the $\mathrm{M}=\mathrm{C}$ bonds to be qualitatively ordered thus: yttrium carbene (alkyl) $<$ yttrium carbene (iodide) $<$ thorium carbene $<$ monophosphanyl uranium carbene $\approx \operatorname{uranyl}(\mathrm{VI})$ carbene $\approx$ hafnium carbene $<$ zirconium carbene $\approx$ uranium(IV) carbene $<$ titanium carbene $\approx$ uranium $(V)$ carbene $<$ uranium(VI) carbene $<$ tantalum(V) alkylidene. This series helps to highlight the nature of the bonding in different 
metal carbene complexes, and reveals that for $\mathrm{U}=\mathrm{C}$ complexes the covalency is highly dependent on the oxidation state as well as the substituted ligands. Moreover it unequivocally show that $\mathrm{U}=\mathrm{C}$ complexes do have significant donation of electron density from the uranium centre to the $\mathrm{U}=\mathrm{C}$ bonding interaction. Whilst coulombic attraction is certainly a feature of the $\mathrm{U}=\mathrm{C}$ bonds discussed here, the fact that they exhibit $\sigma$ - and $\pi$-components and covalency levels approaching transition metal Schrock-type alkylidenes supports the assignment of these $\mathrm{U}=\mathrm{C}$ systems as carbenes. This assignment certainly holds for most of the complexes in Table 1, though it should be noted that carbene complexes of uranyl type derivatives such as 33 and 49 clearly have very polarised $\mathrm{U}=\mathrm{C}$ bonds because the $\{\mathrm{O}=\mathrm{U}=\mathrm{E}\}^{2+}(\mathrm{E}=\mathrm{O}, \mathrm{NMes})$ fragments are already very electron rich. More generally $\mathrm{U}=\mathrm{C}$ double bonds are undoubtedly more polarised than transition metal couterparts, but considerably more covalent that rare earth analogues. 


\section{Summary}

Following Gilje and co-workers pioneering early reports of mono-phosporus-stabilised uranium carbenes, there were limited reports of uranium carbene chemistry for the best part of thirty years. However, more recently there has been a resurgence of interest in this field, with both $\left\{\mathrm{BIPM}^{\mathrm{R}}\right\}^{2-}$ and $\{\mathrm{SCS}\}^{2-}$ ligands finding extensive utility. These ligands have allowed a range of uranium carbenes to be prepared, with ancillary ligands including halides, amides, borohydrides, alkyls, oxos and imides with a variety of oxidation states being observed, including $\mathrm{U}^{\mathrm{IV}}, \mathrm{U}^{\mathrm{V}}$ and both uranyl and non-uranyl $\mathrm{U}^{\mathrm{VI}}$, although examples of $\mathrm{U}^{\mathrm{III}}$ carbenes remain elusive. Combined with these synthetic reports have been reactivity studies, which to date have revealed that the carbon centres of these $\mathrm{U}=\mathrm{C}$ complexes are nucleophilic in nature. Reactions towards ketones and aldehydes have afforded Wittig-type products $(\mathrm{H})(\mathrm{R}) \mathrm{C}=\mathrm{C}\left(\mathrm{PPh}_{2} \mathrm{NSiMe}_{3}\right)_{2}$ such as 57-59 and 66, or in cases where the steric bulk of the substituents on uranium or the carbonyl are too great, a [2+2] cycloaddition product, such as 62-63 or ketone adduct products such as 60 or 67-68, with each of these reaction products being in line with the Wittig-type reactivity of reductive coupling of ketones (Scheme 28). This is a prime example of uranium carbene complexes behaving like Schrock type alkylidenes, ${ }^{25}$ although it should be noted that there are not yet any reports of uranium carbenes reacting with olefins as is the case with Schrock alkylidenes.

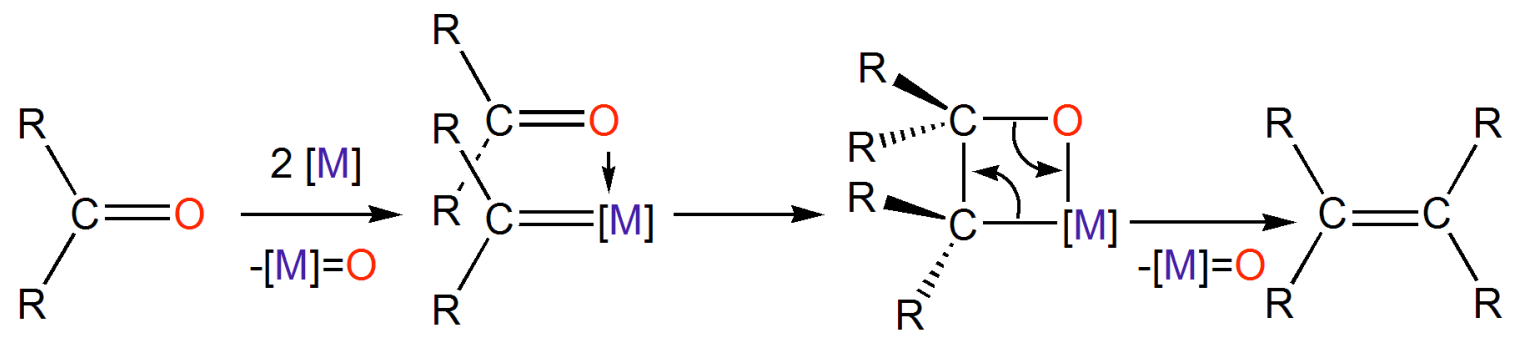

Scheme 28. Reductive coupling of ketones via a carbenoid species.

Although this reactivity type is similar to reactivity shown by the majority of $\{\mathrm{SCS}\}^{2-}$ or $\left\{\mathrm{BIPM}^{\mathrm{R}}\right\}^{2-}$ rare earth complexes, which predominately exhibit Wittig-type reactivity, ${ }^{61,62,68,91}$ 
it is in stark contrast to yttrium $\left\{\mathrm{BIPM}^{\mathrm{TMS}}\right\}^{2-}$ complexes which exhibit unusual reactivity including regioselective $\mathrm{C}-\mathrm{H}$ activation and sequential $\mathrm{C}-\mathrm{C}$ and $\mathrm{C}-\mathrm{O}$ bond formation reactions to afford substituted isobenzofuran products from their reaction with aryl ketones. ${ }^{92-}$

${ }^{95}$ Given that the uranium carbenes discussed herein have been found to react with carbonyls to afford Wittig-type products, akin to Schrock alkylidenes, along with DFT studies that have shown that uranium is capable of modest contributions to the $\mathrm{U}=\mathrm{C}$ carbene bonds, it is clear that the description of these complexes as carbenes is valid. For $c a$. thirty years the only uranium carbenes reported exhibited the $\mathrm{U}^{\mathrm{IV}}$ oxidation state, but since 2011 both $\mathrm{U}^{\mathrm{V}}$ and $\mathrm{U}^{\mathrm{VI}}$ uranium carbenes have been reported. ${ }^{59,72,73}$ Despite this rapid advancement, the preparation of a $\mathrm{U}^{\mathrm{III}}$ carbene remains a synthetic challenge, alongside the removal of phosphorusstabilisation in order to synthesise a 'true' uranium alkylidene complex, which would represent a landmark in synthetic actinide chemistry.

\section{Acknowledgements}

The Authors are grateful for the continued and generous support of the Royal Society, EPSRC, ERC, EU, COST, University of Nottingham, and National Nuclear Laboratory.

\section{References}

1. Bourissou, D.; Guerret, O.; Gabbaï, F. P.; Bertrand, G. Chem. Rev. 1999, 100, 39.

2. Bochmann, M. Organometallics 1 Complexes with Transition Metal-Carbon s-bonds; Oxford University Press: Oxford, 1994.

3. Bochmann, M. Organometallics 2 Complexes with Transition Metal-Carbon p-bonds; Oxford Universtiy Press: Oxford, 1994. 
4. Jacobsen, H.; Correa, A.; Costabile, C.; Cavallo, L. J. Organomet. Chem. 2006, 691, 4350.

5. de Frémont, P.; Marion, N.; Nolan, S. P. Coord. Chem. Rev. 2009, 253, 862.

6. C. Green, J.; G. Scurr, R.; L. Arnold, P.; Geoffrey N. Cloke, F. Chem. Comm. 1997, 1963.

7. Green, J. C.; Herbert, B. J. Dalton Trans. 2005, 1214.

8. Khramov, D. M.; Lynch, V. M.; Bielawski, C. W. Organometallics 2007, 26, 6042.

9. Termaten, A. T.; Schakel, M.; Ehlers, A. W.; Lutz, M.; Spek, A. L.; Lammertsma, K. Chem-Eur J. 2003, 9, 3577.

10. Fantasia, S.; Petersen, J. L.; Jacobsen, H.; Cavallo, L.; Nolan, S. P. Organometallics 2007, 26, 5880 .

11. Hu, X.; Tang, Y.; Gantzel, P.; Meyer, K. Organometallics 2003, $22,612$.

12. Hu, X.; Castro-Rodriguez, I.; Olsen, K.; Meyer, K. Organometallics 2004, 23, 755.

13. Nemcsok, D.; Wichmann, K.; Frenking, G. Organometallics 2004, 23, 3640.

14. Nakai, H.; Hu, X.; Zakharov, L. N.; Rheingold, A. L.; Meyer, K. Inorg. Chem. 2004, 43,855 .

15. Liddle, S. T.; McMaster, J.; Mills, D. P.; Blake, A. J.; Jones, C.; Woodul, W. D. Angew. Chem., Int. Ed. 2009, 48, 1077.

16. Crudden, C. M.; Allen, D. P. Coord. Chem. Rev. 2004, 248, 2247.

17. Herrmann, W. A. Angew. Chem., Int. Ed. 2002, 41, 1290.

18. Hahn, F. E.; Jahnke, M. C. Angew. Chem., Int. Ed. 2008, 47, 3122.

19. Arnold, P. L.; Casely, I. J. Chem. Rev. 2009, 109, 3599.

20. Petasis, N. A.; Bzowej, E. I. J. Am. Chem. Soc. 1990, 112, 6392.

21. Doyle, M. P. Chem. Rev. 1986, 86, 919.

22. Ivin, J. J. Olefin Metathesis; Academic Press: London, 1983. 
23. Anderson, R. B. The Fischer-Tropsch Synthesis; Academic Press: New York, 1984.

24. Hartley, R. C.; McKiernan, G. J. J. Chem. Soc., Perk. T. 1 2002, 2763.

25. Tebbe, F. N.; Parshall, G. W.; Reddy, G. S. J. Am. Chem. Soc. 1978, 100, 3611.

26. Schrock, R. R. Angew. Chem., Int. Ed. 2006, 45, 3748.

27. Chauvin, Y. Angew. Chem., Int. Ed. 2006, 45, 3740.

28. Grubbs, R. H. Angew. Chem., Int. Ed. 2006, 45, 3760.

29. Aparna, K.; Ferguson, M.; Cavell, R. G. J. Am. Chem. Soc. 2000, 122, 726.

30. Liddle, S. T.; McMaster, J.; Green, J. C.; Arnold, P. L. Chem. Comm. 2008, 1747.

31. Liddle, S. T.; Mills, D. P.; Wooles, A. J. Chem. Soc. Rev. 2011, 40, 2164.

32. Ephritikhine, M. C. R. Chim. 2013, 16, 391.

33. Cavell, R. G.; Kamalesh Babu, R. P.; Aparna, K. J. Organomet. Chem. 2001, 617-618, 158.

34. Jones, N. D.; Cavell, R. G. J. Organomet. Chem. 2005, 690, 5485.

35. Römer, B.; Gatev, G. G.; Zhong, M.; Brauman, J. I. J. Am. Chem. Soc. 1998, 120, 2919.

36. El-Nahas, A. M.; Schleyer, P. V. R. J. Comput. Chem. 1994, 15, 596.

37. Schleyer, P. V. R.; Clark, T.; Kos, A. J.; Spitznagel, G. W.; Rohde, C.; Arad, D.; Houk, K. N.; Rondan, N. G. J. Am. Chem. Soc. 1984, 106, 6467.

38. Giesbrecht, G. R.; Gordon, J. C. Dalton Trans. 2004, 2387.

39. Cramer, R. E.; Maynard, R. B.; Paw, J. C.; Gilje, J. W. J. Am. Chem. Soc. 1981, 103, 3589 .

40. Cramer, R. E.; Maynard, R. B.; Paw, J. C.; Gilje, J. W. Organometallics 1982, 1, 869.

41. Cramer, R. E.; Maynard, R. B.; Paw, J. C.; Gilje, J. W. Organometallics 1983, 2, 1336.

42. Pyykkö, P.; Atsumi, M. Chem. Eur. J. 2009, 15, 186.

43. Cramer, R. E.; Bruck, M. A.; Edelmann, F.; Afzal, D.; Gilje, J. W.; Schmidbaur, H. Chem Ber-Recl 1988, 121, 417. 
44. Cramer, R. E.; Jeong, J. H.; Richmann, P. N.; Gilje, J. W. Organometallics 1990, 9, 1141.

45. Cramer, R. E.; Jeong, J. H.; Gilje, J. W. Organometallics 1986, 5, 2555.

46. Cramer, R. E.; Higa, K. T.; Gilje, J. W. J. Am. Chem. Soc. 1984, 106, 7245.

47. Cramer, R. E.; Higa, K. T.; Pruskin, S. L.; Gilje, J. W. J. Am. Chem. Soc. 1983, 105, 6749.

48. Cramer, R. E.; Panchanatheswaran, K.; Gilje, J. W. Angew. Chem., Int. Ed. Eng 1984, 23,912

49. Cramer, R. E.; Panchanatheswaran, K.; Gilje, J. W. J. Am. Chem. Soc. 1984, 106, 1853.

50. Cramer, R. E.; Engelhardt, U.; Higa, K. T.; Gilje, J. W. Organometallics 1987, 6, 41.

51. Gilje, J. W.; Cramer, R. E.; Bruck, M. A.; Higa, K. T.; Panchanetheswaran, K. Inorg Chim a-F-Block 1985, 110, 139.

52. Stevens, R. C.; Bau, R.; Cramer, R. E.; Afzal, D.; Gilje, J. W.; Koetzle, T. F. Organometallics 1990, 9, 694.

53. Fortier, S.; Walensky, J. R.; Wu, G.; Hayton, T. W. J. Am. Chem. Soc. 2011, 133, 6894.

54. Cornish, A. D.; Mills, D. P.; Lewis, W.; Blake, A. J.; Liddle, S. T. C. R. Chim. 2010, 13,593 .

55. Alcarazo, M.; Lehmann, C. W.; Anoop, A.; Thiel, W.; Fürstner, A. Nat. Chem. 2009, 1, 295.

56. Cantat, T.; Arliguie, T.; Noel, A.; Thuery, P.; Ephritikhine, M.; Le, F. P.; Mezailles, N. J. Am. Chem. Soc. 2009, 131, 963.

57. Tourneux, J.-C.; Berthet, J.-C.; Cantat, T.; Thuery, P.; Mezailles, N.; Le, F. P.; Ephritikhine, M. Organometallics 2011, 30, 2957.

58. Tourneux, J.-C.; Berthet, J.-C.; Thuery, P.; Mezailles, N.; Le, F. P.; Ephritikhine, M. Dalton Trans. 2010, 39, 2494. 
59. Tourneux, J.-C.; Berthet, J.-C.; Cantat, T.; Thuery, P.; Mezailles, N.; Ephritikhine, M. J. Am. Chem. Soc. 2011, 133, 6162.

60. Shannon, R. D. Acta Crystallogr. Sect. A 1976, 32, 751.

61. Fustier, M.; Le Goff, X. F.; Le Floch, P.; Mézailles, N. J. Am. Chem. Soc. 2010, 132, 13108.

62. Cantat, T.; Jaroschik, F.; Nief, F.; Ricard, L.; Mezailles, N.; Le Floch, P. Chem. Comm. 2005, 5178.

63. Cooper, O. J.; McMaster, J.; Lewis, W.; Blake, A. J.; Liddle, S. T. Dalton Trans. 2010, $39,5074$.

64. Cooper, O. J.; Mills, D. P.; McMaster, J.; Tuna, F.; McInnes, E. J. L.; Lewis, W.; Blake, A. J.; Liddle, S. T. Chem-Eur. J 2013, 19, 7071.

65. Wooles, A. J.; Gregson, M.; Robinson, S.; Cooper, O. J.; Mills, D. P.; Lewis, W.; Blake, A. J.; Liddle, S. T. Organometallics 2011, 30, 5326.

66. Wooles, A. J.; Gregson, M.; Cooper, O. J.; Middleton-Gear, A.; Mills, D. P.; Lewis, W.; Blake, A. J.; Liddle, S. T. Organometallics 2011, 30, 5314.

67. Marshall, G.; Wooles, A.; Mills, D.; Lewis, W.; Blake, A.; Liddle, S. Inorganics 2013, 1,46 .

68. Gregson, M.; Lu, E.; McMaster, J.; Lewis, W.; Blake, A. J.; Liddle, S. T. Angew. Chem., Int. Ed. 2013, 52, 13016.

69. Mills, D. P.; Moro, F.; McMaster, J.; van, S. J.; Lewis, W.; Blake, A. J.; Liddle, S. T. Nat. Chem. 2011, 3, 454.

70. Ma, G. B.; Ferguson, M. J.; McDonald, R.; Cavell, R. G. Inorg. Chem. 2011, 50, 6500.

71. Mills, D. P.; Wooles, A. J.; McMaster, J.; Lewis, W.; Blake, A. J.; Liddle, S. T. Organometallics 2009, 28, 6771. 
72. Cooper, O. J.; Mills, D. P.; McMaster, J.; Moro, F.; Davies, E. S.; Lewis, W.; Blake, A. J.; Liddle, S. T. Angew. Chem., Int. Ed. 2011, 50, 2383.

73. Mills, D. P.; Cooper, O. J.; Tuna, F.; McInnes, E. J. L.; Davies, E. S.; McMaster, J.; Moro, F.; Lewis, W.; Blake, A. J.; Liddle, S. T. J. Am. Chem. Soc. 2012, 134, 10047.

74. Denning, R. G. In Complexes, Clusters and Crystal Chemistry; Springer Berlin Heidelberg: 1992; Vol. 79, p 215.

75. Fortier, S.; Wu, G.; Hayton, T. W. J. Am. Chem. Soc. 2010, 132, 6888.

76. Lam, O. P.; Franke, S. M.; Nakai, H.; Heinemann, F. W.; Hieringer, W.; Meyer, K. Inorg. Chem. 2012, 51, 6190.

77. Kosog, B.; La Pierre, H. S.; Heinemann, F. W.; Liddle, S. T.; Meyer, K. J. Am. Chem. Soc. 2012, 134, 5284.

78. O'Grady, E.; Kaltsoyannis, N. J. Chem. Soc., Dalton Trans. 2002, 1233.

79. King, D. M.; Tuna, F.; McInnes, E. J. L.; McMaster, J.; Lewis, W.; Blake, A. J.; Liddle, S. T. Nat. Chem. 2013, 5, 482.

80. King, D. M.; Tuna, F.; McMaster, J.; Lewis, W.; Blake, A. J.; McInnes, E. J. L.; Liddle, S. T. Angew. Chem. Int. Ed. 2013, 52, 4921.

81. Lewis, A. J.; Carroll, P. J.; Schelter, E. J. J. Am. Chem. Soc. 2013, 135, 13185.

82. Allen, F. H. Acta Crystallog. Sect. B 2002, 58.

83. Lu, E.; Cooper, O. J.; McMaster, J.; Tuna, F.; McInnes, E. J. L.; Lewis, W.; Blake, A. J.; Liddle, S. T. Angew. Chem., Int. Ed. 2014, 53, 6696.

84. Liddle, S. T.; Mills, D. P.; Gardner, B. M.; McMaster, J.; Jones, C.; Woodul, W. D. Inorg. Chem. 2009, 48, 3520.

85. Wooles, A. J.; Cooper, O. J.; McMaster, J.; Lewis, W.; Blake, A. J.; Liddle, S. T. Organometallics 2010, 29, 2315. 
86. Wooles, A. J.; Mills, D. P.; Lewis, W.; Blake, A. J.; Liddle, S. T. Dalton Trans. 2010, $39,500$.

87. Schumann, H.; Mueller, J.; Bruncks, N.; Lauke, H.; Pickardt, J.; Schwarz, H.; Eckart, K. Organometallics 1984, 3, 69.

88. Ruspic, C.; Moss, J. R.; Schürmann, M.; Harder, S. Angew. Chem., Int. Ed. 2008, 47, 2121.

89. Cooper, O. J.; Wooles, A. J.; McMaster, J.; Lewis, W.; Blake, A. J.; Liddle, S. T. Angew. Chem., Int. Ed. 2010, 122, 5702.

90. Cooper, O. J.; Mills, D. P.; Lewis, W.; Blake, A. J.; Liddle, S. T. Dalton Trans. 2014, $43,14275$.

91. Cantat, T.; Jaroschik, F.; Ricard, L.; Le Floch, P.; Nief, F.; Mézailles, N. Organometallics 2006, 25, 1329.

92. Mills, D. P.; Soutar, L.; Lewis, W.; Blake, A. J.; Liddle, S. T. J. Am. Chem. Soc. 2010, 132,14379 .

93. Mills, D. P.; Cooper, O. J.; McMaster, J.; Lewis, W.; Liddle, S. T. Dalton Trans. 2009, 4547.

94. Mills, D. P.; Soutar, L.; Cooper, O. J.; Lewis, W.; Blake, A. J.; Liddle, S. T. Organometallics 2013, 32, 1251.

95. Mills, D. P.; Lewis, W.; Blake, A. J.; Liddle, S. T. Organometallics 2013, 32, 1239. 